УДК 004.8

01.00.00 Физико-математические науки

НЕЧЕТКОЕ МУЛЬТИКЛАССОВОЕ
ОБОБЩЕНИЕ КЛАССИЧЕСКОЙ Ғ-МЕРЫ
ДОСТОВЕРНОСТИ МОДЕЛЕЙ ВАН
РИЗБЕРГЕНА В АСК-АНАЛИЗ И СИСТЕМЕ
«ЙДОС»

Луценко Евгений Вениаминович, д.э.н., к.т.н., профессор Scopus Author ID: 57191193316

РИНЦ SPIN-код: 9523-7101

prof.lutsenko@gmail.com

Кубанский государственный аграрный университет имени И.Т.Трубилина, Краснодар, Россия

Классическая количественная мера достоверности моделей: F-мера Ван Ризбергена основана на подсчете суммарного количества верно и ошибочно классифицированных и не классифицированных объектов обучающей выборки. В мультиклассовых системах классификации объект может одновременно относится ко многим классам. Соответственно, при синтезе модели его описание используется для формирования обобщенных образов многих классов, к которым он относится. При использовании модели для классификации определяется степень сходства-различия объекта со всеми классами, причем истинно-положительным решением может являться принадлежность объекта сразу к нескольким классам. В результате такой классификации получается, что объект не просто правильно или ошибочно относится или не относится к различным классам, как в классической F-мере, но правильно или ошибочно относится или не относится к ним в различной степени. Однако классическая F-мера не учитывает того, что объект может фактически одновременно относится ко многим классам (мультиклассовость) и того, что в результате классификации может быть получена различная степень сходства-различия объекта с классами (нечеткость). На численных примерах автором установлено, что при истинноположительных и истинно-отрицательных решениях модуль сходства-различия объекта с классами значительно выше, чем при ложно-положительных и ложно-отрицательных решениях. Поэтому было бы рационально в мере достоверности модели учитывать не просто сам факт истинно или ложно положительного или отрицательного решения, но и учитывать степень уверенности классификатора в этих решениях. В интеллектуальной системе «Эйдос», которая является программным инструментарием автоматизированного системнокогнитивного анализа (АСК-анализ), изначально используется предложенная их разработчиком мера достоверности моделей, по сути являющаяся нечетким мультиклассовым обобщением классиче-
UDC 004.8

Physics and mathematical sciences

\section{FUZZY MULTICLASS GENERALIZATION \\ OF THE CLASSICAL F-MEASURE OF PLAUSIBILITY MODELS BY VAN RIJSBERGEN IN ASK-THE ANALYSIS AND THE SYSTEM OF "EIDOS"}

Lutsenko Eugeny Veniaminovich

Dr.Sci.Econ., Cand.Tech.Sci., professor

Scopus Author ID: 57191193316

RSCI SPIN-code: 9523-7101

prof.lutsenko@gmail.com

Kuban State Agrarian University, Krasnodar, Russia

Classic quantitative measure of the reliability of the models: F-measure by van Rijsbergen is based on counting the total number of correctly and incorrectly classified and not classified objects in the training sample. In multiclass classification systems, the facility can simultaneously apply to multiple classes. Accordingly, when the synthesis of the model description is used for formation of generalized images of many of the classes it belongs to. When using the model for classification, it is determined by the degree of similarity or divergence of the object with all classes, and a true-positive decision may be the membership of the object to several classes. The result of this classification may be that the object is not just rightly or wrongly relates or does not relate to different classes, both in the classical F-measure, but rightly or wrongly relates or does not relate to them in varying degrees. However, the classic Fmeasure does not count the fact that the object may in fact simultaneously belongs to multiple classes (multicrossover) and the fact that the classification result can be obtained with a different degree of similarity-differences of object classes (blurring). In the numerical example, the author states that with true-positive and true-negative decisions, the module similarities-differences of the object classes are much higher than for false-positive and falsenegative decisions. It would therefore be rational to the extent that the reliability of the model to take into account not just the fact of true or false positive or negative decisions, but also to take into account the degree of confidence of the classifier in these decisions. In the intellectual system called "Eidos", which is a software toolkit for the automated system-cognitive analysis (ASC-analysis), we use initially proposed by its developers measure of the reliability of the models, which is essentially a fuzzy multiclass generalization of the classical F-measure (it is proposed to call it the L-measure). In this article, L-measure is mathematically described and its application is demonstrated on a simple numerical example 
ской F-меры (предлагается называть еe L-мерой). B данной статье L-мера описана математически и еe применение продемонстрировано на простом численном примере

Ключевые слова: НЕЧЕТКОЕ МУЛЬТИКЛАССОВОЕ ОБОБЩЕНИЕ, КЛАССИЧЕСКАЯ F-МЕРА ДОСТОВЕРНОСТИ МОДЕЛЕЙ ВАН РИЗБЕРГЕНА, АСК-АНАЛИЗ, ИНТЕЛЛЕКТУАЛЬНАЯ СИСТЕМА «ЭЙДОС»
Keywords: FUZZY MULTICLASS GENERALIZATION, CLASSICAL F-MEASURE OF PLAUSIBILITY FOR VAN RIJSBERGEN MODELS, ASC-ANALYSIS, "EIDOS" INTELLECTUAL SYSTEM

Doi: 10.21515/1990-4665-123-001

\section{СОДЕРЖАНИЕ}

ВВЕДЕНИЕ

1. ОПИСАНИЕ КЛАССИЧЕСКОЙ Ғ-МЕРЫ ВАН РИЗБЕРГЕНА

1.1. КРАТКОЕ ТРАДИЦИОННОЕ ОПИСАНИЕ F-МЕРЫ ВАН РИЗБЕРГЕНА ..................................................... 4

1.2. F-МЕРА ВАН РИЗБЕРГЕНА В ОБЫЧНЫХ МАТЕМАТИЧЕСКИХ ОБОЗНАЧЕНИЯХ ........................................ 5

\section{2. ОПИСАНИЕ L-МЕРЫ: НЕЧЕТКОГО МАЛЬТИКЛАССОВОГО ОБОБЩЕНИЯ}

\section{КЛАССИЧЕСКОЙ Ғ-МЕРЫ ВАН РИЗБЕРГЕНА ...................................................................................... 8}

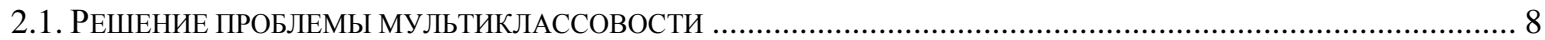

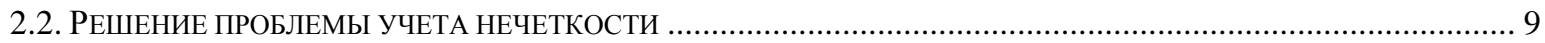

2.3. АСИМПТОТИЧЕСКОЕ ВЫПОЛНЕНИЕ ДЛЯ L-МЕРЫ ПРИНЦИПА СООТВЕТСТВИЯ С F-МЕРОЙ ВАН

РИЗБЕРГЕНА

4. ЧИСЛЕННЫЙ ПРИМЕР ПРИМЕНЕНИЯ L-МЕРЫ И СРАВНЕНИЕ L-MЕРЫ С F-МЕРОЙ .... 11

ВЫВОДЫ

ЛИТЕРАТУРА

\section{Введение}

Классическая количественная мера достоверности моделей: F-мера Ван Ризбергена $[1,2]$ основана на подсчете суммарного количества верно и ошибочно классифицированных и не классифицированных объектов обучающей выборки .

В мультиклассовых системах классификации объект может одновременно относится ко многим классам. Соответственно при синтезе модели его описание используется для формирования обобщенных образов многих классов, к которым он относится. При использовании модели для классификации количественно определяется степень сходства-различия объекта со всеми классами, причем истинно-положительным решением 
может являться принадлежность объекта сразу к нескольким классам. В результате такой классификации обычно получается, что объект не просто правильно или ошибочно относится или не относится к различным классам, как в классической F-мере, но правильно или ошибочно относится или не относится к ним в различной степени.

Однако классическая F-мера не учитывает того, что объект может фактически одновременно относится ко многим классам (мультиклассовость) и того, что в результате классификации может быть получена различная степень сходства-различия объекта с классами (нечеткость решений классификатора).

На многочисленных численных примерах из различных предметных областей автором установлено, что при истинно-положительных и истинно-отрицательных решениях модуль сходства-различия объекта с классами как правило значительно выше, чем при ложно-положительных и ложноотрицательных решениях. Это навело на мысль, что было бы рационально и обоснованно в мере достоверности модели учитывать не просто сам факт истинно или ложно положительного или отрицательного решения, но и учитывать степень уверенности классификатора в этих решениях.

В интеллектуальной системе «Эйдос», которая является программным инструментарием автоматизированного системно-когнитивного анализа (АСК-анализ), изначально [3, 4, 5] используется предложенная их разработчиком проф. Е.В. Луценко мера достоверности моделей, сходная по форме с коэффициентом корреляции Мэтью [6] и по сути являющаяся нечетким мультиклассовым обобщением классической F-меры (предлагается называть еe L-мерой проф. Е.В. Луценко ${ }^{1}$ ).

\footnotetext{
${ }^{1}$ Автор делает это без ложной скромности, т.к. у него есть отрицательный опыт, когда предложенные и математически обоснованные им количественные меры уровня системности и степени детерминированности систем были названы им в честь выдающихся ученых, внесших большой вклад в развитие теории информации коэффициентами эмерджентности Хартли, Харкевича и Шеннона $[4,5]$. В результате теперь очень многие думают, что эти коэффициенты эмерджентности были предложены этими учеными и часто пишут об этом в своих работах, ссылаясь на них, а не на их автора. Чтобы убедиться в этом достаточно
} 
B данной статье эта L-мера описана математически и ее применение продемонстрировано на простом численном примере.

\section{1. Описание классической F-меры Ван Ризбергена}

\section{1. Краткое традиционное описание F-меры Ван Ризбер- гена}

Классическая количественная мера достоверности моделей: F-мера Ван Ризбергена вряд ли нуждается в описании в данной статье, т.к. в Internet есть более чем достаточно ее прекрасных описаний из которых автор все же выделил бы работу [2].

Ниже приводится пространная выдержка из этой работы.

«Точность (precision) и полнота (recall) являются метриками которые используются при оценке большей части алгоритмов извлечения информации. Иногда они используются сами по себе, иногда в качестве базиса для производных метрик, таких как F-мера или R-Precision. Суть точности и полноты очень проста.

Точность системы в пределах класса - это доля документов действительно принадлежащих данному классу относительно всех документов которые система отнесла к этому классу.

Полнота системы - это доля найденных классификатором документов принадлежащих классу относительно всех документов этого класса в тестовой выборке.

Эти значения легко рассчитать на основании таблицы контингентности, которая составляется для каждого класса отдельно. 


\begin{tabular}{|c|c|c|c|}
\hline \multirow{2}{*}{ Категория i } & \multicolumn{2}{|c|}{ Экспертная оценка } \\
\cline { 2 - 4 } & Положительная & Отрицательная \\
\hline \multirow{2}{*}{ Оценка системы } & Положительная & TP & FP \\
\cline { 2 - 4 } & Отрицательная & FN & TN \\
\hline
\end{tabular}

В таблице содержится информация сколько раз система приняла верное и сколько раз неверное решение по документам заданного класса. А именно:

- ТР - истино-положительное решение;

- $\mathrm{TN}$ - истино-отрицательное решение;

- FР - ложно-положительное решение;

- $\mathrm{FN}$ - ложно-отрицательное решение.

Тогда, точность и полнота определяются следующим образом:

$$
\begin{aligned}
& \text { Precision }=\frac{\mathrm{TP}}{\mathrm{TP}+\mathrm{FP}} \\
& \text { Recall }=\frac{\mathrm{TP}}{\mathrm{TP}+\mathrm{FN}}
\end{aligned}
$$

F-мера - характеристика, которая позволяет дать оценку достоверности модели одновременно по точности и полноте:

$$
\mathrm{F}=\frac{2 * \text { Precision } * \text { Recall }}{\text { Precision } * \text { Recall }}
$$

\subsection{F-мера Ван Ризбергена в обычных математических обозначениях}

Конечно понятно, что:

- ТР - истино-положительное решение;

- $\mathrm{TN}$ - истино-отрицательное решение;

- FP - ложно-положительное решение;

- $\mathrm{FN}$ - ложно-отрицательное решение.

это не просто истинно и ложно положительные и отрицательные решения, а их количество или суммы при классификации всех объектов тестовой выборки по всем классам с помощью модели. В простейшем случае для 
тестирования модели может использоваться обучающая выборка, на основе которой она создана. В более сложных вариантах оценки достоверности модели может быть применен бутстрепный подход или как тестовая выборка использовано подмножество генеральной совокупности, по отношению к которой репрезентативна обучающая выборка.

Запишем это, используя обычные математические обозначения, в т.ч. знаки суммы. Нам это потребуется в последующем для математической записи предлагаемой L-меры.

В обсуждении работы [2] рассматривается два подхода к оценке достоверности модели: «micro-averaging» и «macro-averaging».

Micro-averaging - точность, полнота и F-мера вычисляется для каждого класса, а затем F-мера модели в целом рассчитывается как среднее Fмер по классам.

Macro-averaging - точность и полнота рассчитываются по всей модели в целом (при классификации всех объектов тестовой выборки по всем классам), а затем на их основе рассчитывается F-мера модели в целом.

Мы будем использовать подход: «macro-averaging», хотя и F-меру и по классам, и даже по объектам по ходу расчета F-меры модели в целом мы также посчитаем.

Введем следующие обозначения:

$T$ - число объектов тестовой выборки;

$K$ - число классов;

$i$ - номер (код) объекта тестовой выборки;

$j$ - номер (код) класса;

$A$ - суммарное по всей модели (по всем классам и всем объектам тестовой выборки) число истино-положительных решений (ТР - число объектов, правильно отнесенных к классам, к которым они действительно относятся); 
$B$ - суммарное по всей модели (по всем классам и всем объектам тестовой выборки) число истино-отрицательных решений (TN - число объектов, правильно не отнесенных к классам, к которым они действительно не относятся);

$C$ - суммарное по всей модели (по всем классам и всем объектам тестовой выборки) число ложно-положительных решений (FP - число объектов, неправильно отнесенных к классам, к которым они на самом деле не относятся);

$D$ - суммарное по всей модели (по всем классам и всем объектам тестовой выборки) число ложно-отрицательных решений (FN - число объектов, неправильно не отнесенных к классам, к которым они на самом деле относятся);

$P$ - точность модели;

$R$ - полнота модели;

В этих обозначениях точность, полнота и F-мера модели определяются следующим образом:

$$
\begin{aligned}
& P=\frac{A}{A+C}, \\
& R=\frac{A}{A+D}, \\
& F=\frac{2 P R}{P+R} .
\end{aligned}
$$

Здесь A, C, D рассчитываются следующим образом:

$$
\begin{gathered}
A=\sum_{i=1}^{T} \sum_{j=1}^{K} 1, \\
C=\sum_{i=1}^{T} \sum_{j=1}^{K} 1, \\
D=\sum_{i=1}^{T} \sum_{j=1}^{K} 1 .
\end{gathered}
$$




\section{2. Описание L-меры: нечеткого мальтиклассового обоб- щения классической F-меры Ван Ризбергена}

\section{1. Решение проблемы мультиклассовости}

Если физический объект обучающей выборки одновременно относится к $\mathrm{N}$ классам, то его можно рассматривать как линейную суперпозицию $\mathrm{N}$ логических объектов, каждый из которых относится к одному из этих $\mathrm{N}$ классов. Здесь используется терминология автоматизированного системно-когнитивного анализа (АСК-анализ).

Так в работе [8] автор еще в 1996 году писал: «Физическая анкета это анкета, заполненная респондентом. Но этот респондент может относится одновременно ко многим градациям шкал классификации классов распознавания (см. 2.1.1.1, 2.1.1.2), т.е. быть одновременно, например, мужчиной, иметь определенный возраст, определенную национальность, определенную форму занятости и т.д., и т.п. Следовательно одну физическую анкету можно использовать для формирования обобщенных образов каждой из этих категорий, к которым относится заполнявший ее респондент. Это и означает, что одна физическая анкета рассматривается как включающая некоторое количество логических анкет» ${ }^{2}$.

В настоящее время в АСК-анализе говорится не о физических и логических анкетах, о физических и логических объектах, которые являются более общим понятием, чем анкеты, а анкеты - это частный случай объектов, но суть от этого не меняется, т.к. один мультиклассовый объект, т.е. относящийся одновременно ко многим классам, рассматривается как много моноклассовых объектов, каждый из которых относится к одному из этих классов. При этом моноклассовые объекты наследуют описание на

\footnotetext{
${ }^{2}$ http://lc.kubagro.ru/aidos/aidos96/3.htm 
языке признаков от мультиклассового объекта, т.е. описываются ими так же, как он.

\section{2. Решение проблемы учета нечеткости}

При расчете L-меры предлагается рассчитывать A, C, D следующим образом:

$$
\begin{aligned}
& A=\sum_{i=1}^{T} \sum_{j=1}^{K} \mid A[i, j], \\
& C=\sum_{i=1}^{T} \sum_{j=1}^{K} \mid C[i, j], \\
& D=\sum_{i=1}^{T} \sum_{j=1}^{K} \mid D[i, j],
\end{aligned}
$$

Т.е. суммировать не единицы, а модули уровня сходства-различия объектов с классами для разных исходов классификации (верных и ошибочных, положительных и отрицательных ):

$A[i, j]=$ уровень сходства-различия $i$-го объекта с $j$-м классом в соответствии с моделью при истино-положительных решениях;

$C[i, j]=$ уровень сходства-различия $i$-го объекта с $j$-м классом в соответствии с моделью при истино-отрицательных решениях;

$D[i, j]=$ уровень сходства-различия $i$-го объекта с $j$-м классом в соответствии с моделью при ложно-отрицательных решениях.

Так как модули уровня сходства-различия объектов с классами при истинных решениях значительно выше, чем при ложных, то L-мера на много точнее отражает уровень достоверности модели, чем классическая F-мера Ван Ризбергена. Более того, если учитывать только те решения, которые по модулю уровня сходства-различия выше, чем ложные, то можно 
вообще отфильтровать ложные решения, как положительные, так и отрицательные.

\section{3. Асимптотическое выполнение для L-меры принципа со- ответствия с F-мерой Ван Ризбергена}

Известно, что более общие модели включают в себя частные и в предельном случае асимптотически переходят в них, т.е. удовлетворяют принципу соответствия, и это является обязательным для более общих теорий ${ }^{3}$.

Возникает естественный вопрос о том, выполняется ли этот фундаментальный методологический принцип для L-меры и F-меры.

Ответ на этот вопрос совершенно элементарен и очевиден: «конечно соответствует». Убедиться в этом просто. Для этого достаточно, чтобы уровни сходства-различия $i$-го объекта с $j$-м классом в соответствии с моделью при истино-положительных, истино-отрицательных и ложноотрицательных решениях асимптотически стремились к 1 :

$$
\begin{aligned}
& A[i, j] \rightarrow 1, \\
& C[i, j] \rightarrow 1, \\
& D[i, j] \rightarrow 1 .
\end{aligned}
$$

Тогда выражения (5) асимптотически перейдут в (4), и L-мера в Fмеру. Проще говоря, если в некоторой модели считать, что объект относится к классу, если уровень сходства объекта с классом больше нуля, и считать что не относится, если уровень сходства объекта с классом меньше нуля, то L-мера переходит в классическую F-меру Ван Ризбергена.

\footnotetext{
${ }^{3}$ См., например: http://dic.academic.ru/dic.nsf/enc_philosophy/7345/СООТВЕТСТВИЯ 


\section{4. Численный пример применения L-меры и сравнение L- меры с F-мерой}

Кратко рассмотрим простой численный пример, наглядно иллюстрирующий вышеизложенные теоретические положения.

Для численного примера используем лабораторную работу 3.03, встроенную в интеллектуальную систему «Эйдос», которая является программным инструментарием АСК-анализа.

Для этого скачиваем систему «Эйдос» с сайта автора по адресу: http://lc.kubagro.ru/aidos/_Aidos-X.htm и запускаем еe, следуя инструкциям на сайте.

Затем в режиме 1.3 устанавливаем лабораторную работу 3.03 , следуя инструкциям системы с параметрами по умолчанию. При этом в приведенной последовательности будут открываться следующие экранные формы, представленные на рисунке 1:

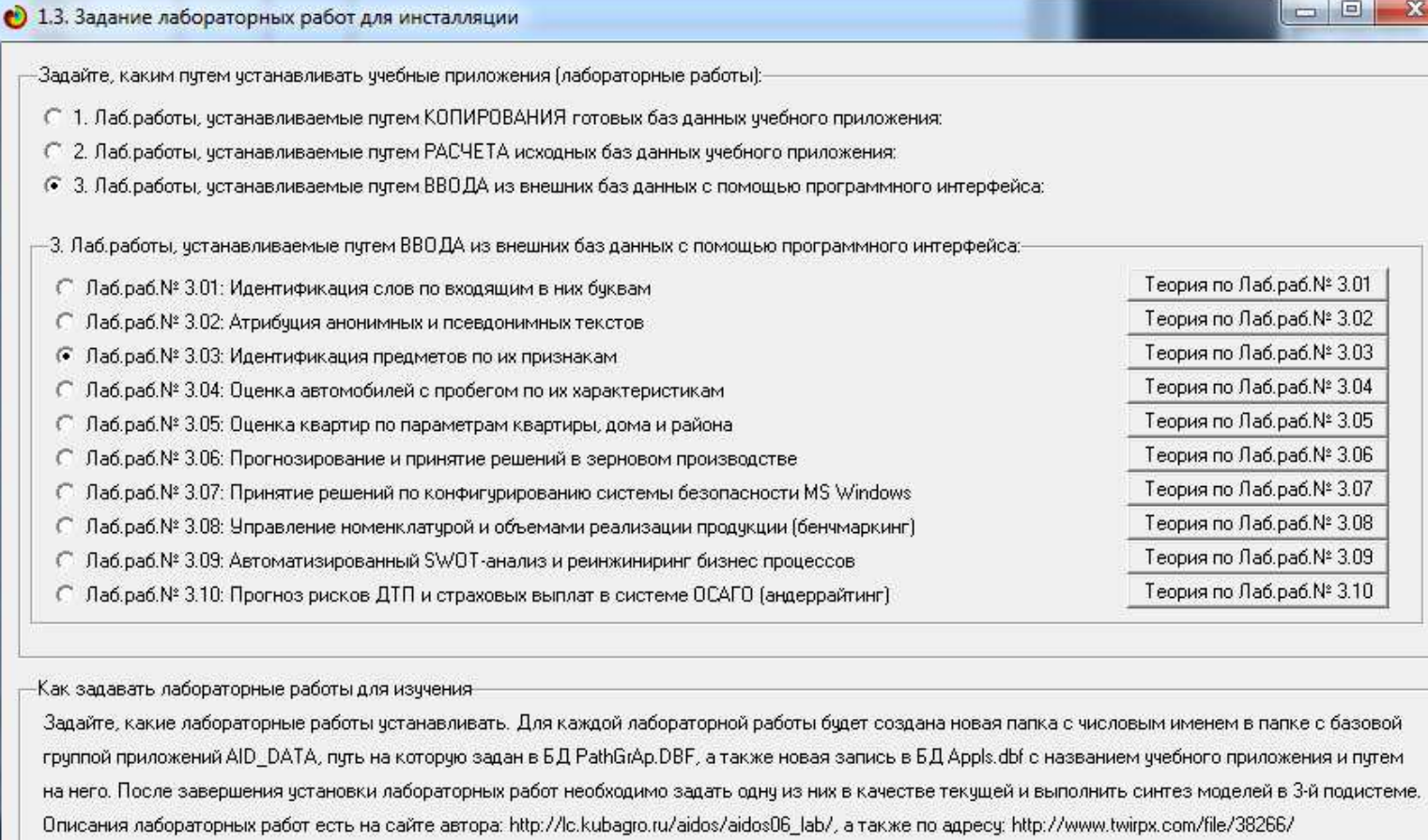

Теория по Лаб.ра6.№ 3.01

Теория по Лаб.pa6.№ 3.02

Теория по Ла6.pa6. № 3.03

Теория по Лаб.ра6.№ 3.04

Теория по Лаб. paб. $N$ 3.05

Теория по Лla6. pa6.№ 3.06

Теория по Лаб.раб.N 3.07

Теория по Лаб.pa6.№ 3.08

Теория по Ла6.pa6.Nㅡ‥09

Теория по Лаб.ра6.№ 3.10

Как задавать лабораторные работы для изучения

Задайте, какие лабораторные работы устанавливать. Для каждой лабораторной работы будет создана новая папка с числовым именем в папке с базовой группой приложений AID_DATA, путь на которую задан в БД PathG rAp.DBF, а также новая запись в БД_Appls.dbf с названием учебного приложения и путем на него. После завершения установки лабораторных работ необходимо задать одну из них в качестве текущей и выполнить синтез моделей в 3-й подистеме. Описания лабораторных работ есть на сайте автора: http://c.kubagro.ru/aidos/aidos06_lab/, a также по aдpecy: http://www.twirpx.com/file/38266/

$\underline{\text { Qk }}$ 


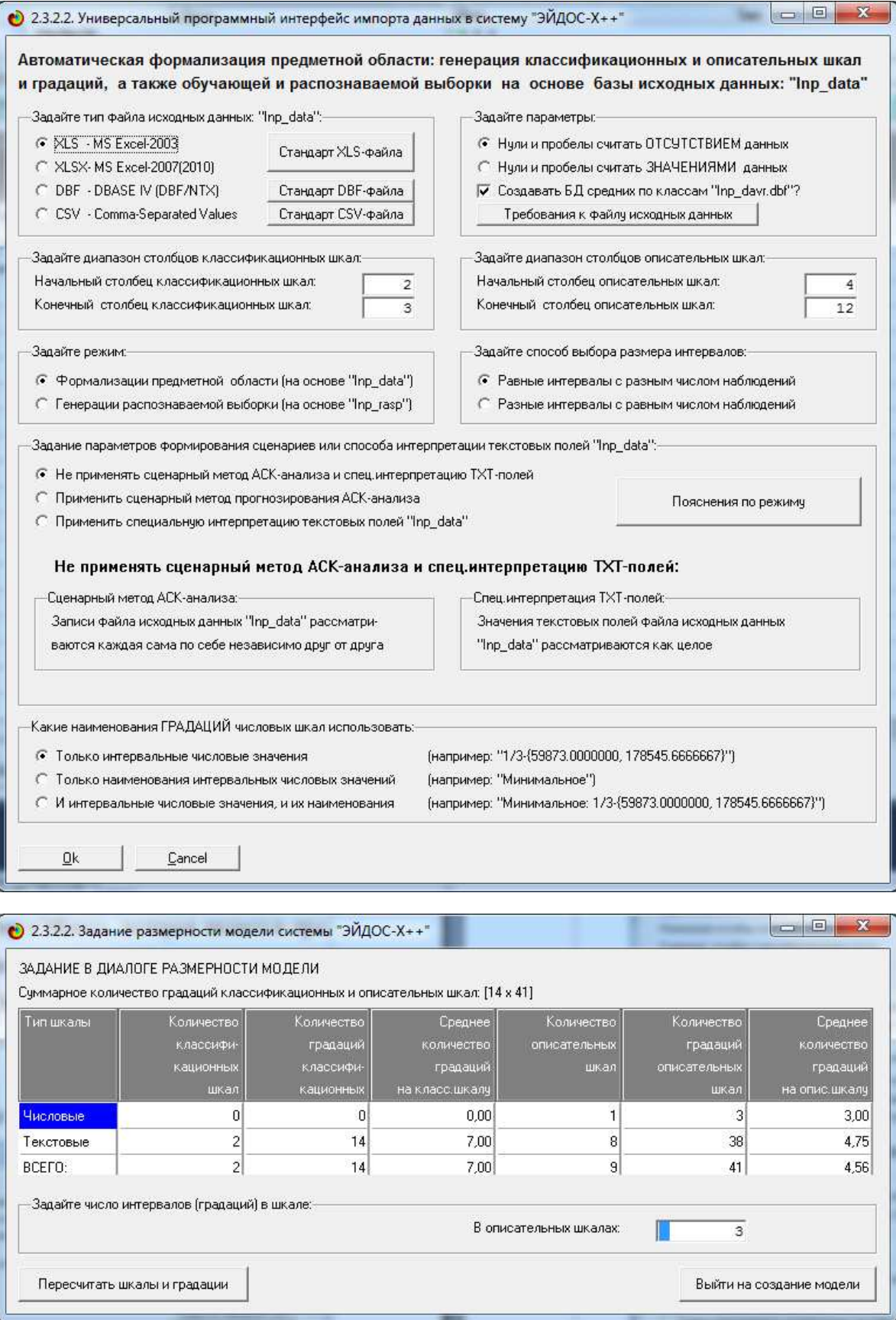

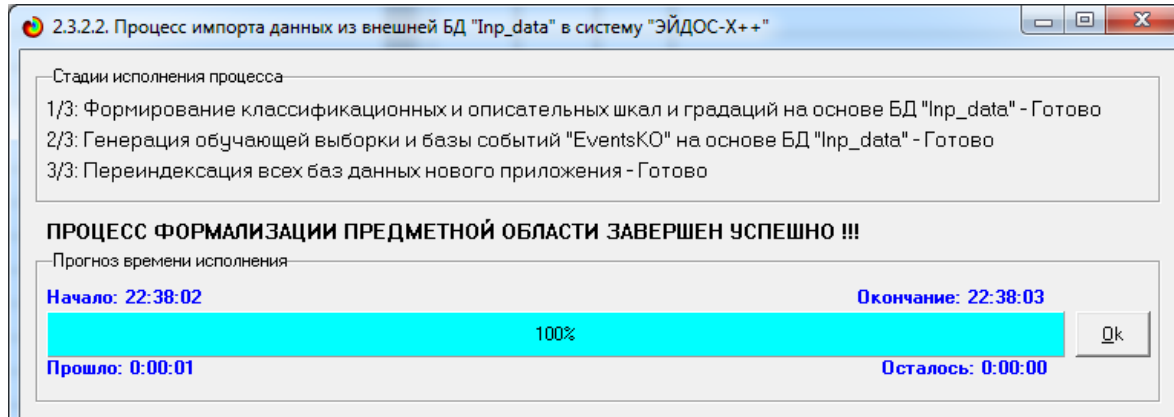




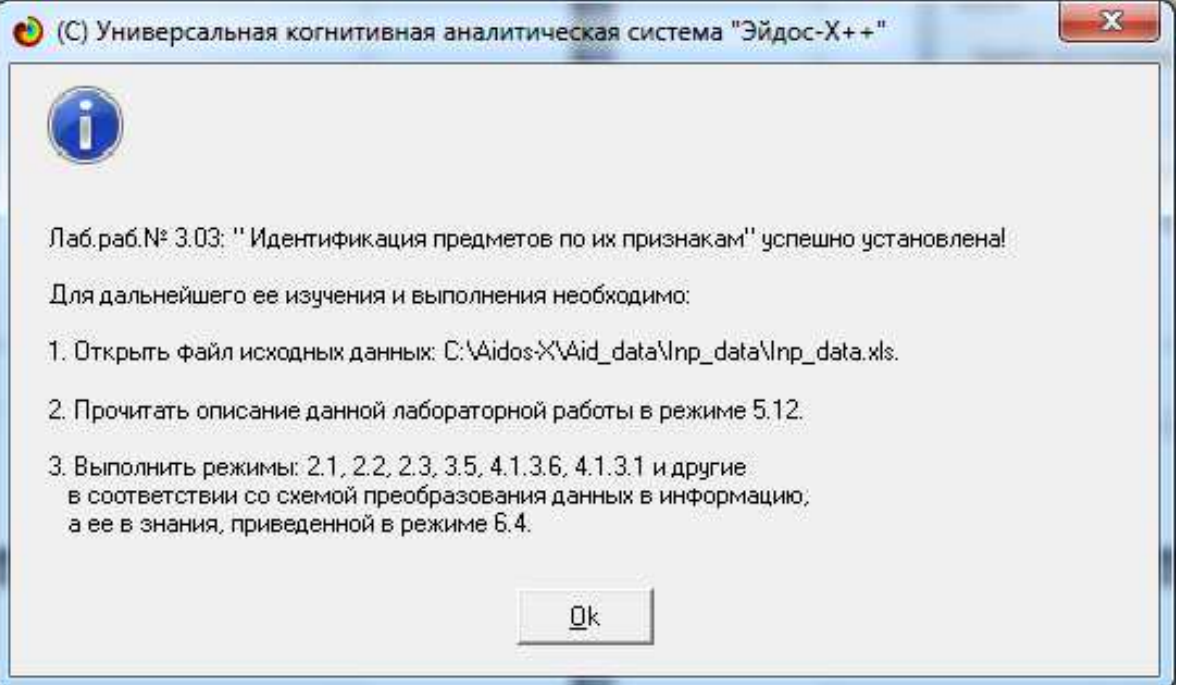

Рисунок 1. Экранные формы системы «Эйдос», открывающиеся при установке встроенной лабораторной работы 3.03.

\section{Далее следуем инструкциям, представленным на последнем окне.}

\section{Таблица 1 - Исходные данные для построения модели}

\begin{tabular}{|c|c|c|c|c|c|c|c|c|c|c|c|}
\hline Объект & $\begin{array}{l}\text { Конкрет- } \\
\text { ный класс }\end{array}$ & $\begin{array}{c}\text { Обобщающий } \\
\text { класс }\end{array}$ & Цвет & $\begin{array}{l}\text { Матери- } \\
\text { ал }\end{array}$ & $\begin{array}{c}\text { Размер- } \\
1\end{array}$ & $\begin{array}{l}\text { Раз- } \\
\text { мер-2 }\end{array}$ & $\begin{array}{c}\text { Нали- } \\
\text { чие } \\
\text { экрана }\end{array}$ & $\begin{array}{c}\text { Нали- } \\
\text { чие } \\
\text { кнопок }\end{array}$ & $\begin{array}{l}\text { Нали- } \\
\text { чие } \\
\text { прово- } \\
\text { дов }\end{array}$ & Формы & $\begin{array}{c}\text { Нали- } \\
\text { чие } \\
\text { ножек }\end{array}$ \\
\hline Мышь1 & Мышка & $\begin{array}{l}\text { элемент компью- } \\
\text { тера }\end{array}$ & Черный & \begin{tabular}{|l|} 
Пласт- \\
маса
\end{tabular} & под руку & 8,00 & нет & есть & есть & округлая & нет \\
\hline Мышь2 & мышка & $\begin{array}{l}\text { элемент компью- } \\
\text { тера }\end{array}$ & Белый & \begin{tabular}{|l} 
Пласт- \\
маса
\end{tabular} & под руку & 8,00 & нет & есть & есть & округлая & нет \\
\hline мышь3 & мышка & $\begin{array}{l}\text { элемент компью- } \\
\text { тера }\end{array}$ & серый & \begin{tabular}{|l} 
Пласт- \\
маса
\end{tabular} & под руку & 8,00 & нет & есть & есть & округлая & нет \\
\hline клавиатура1 & $\begin{array}{l}\text { клавиату- } \\
\text { ра }\end{array}$ & $\begin{array}{l}\text { элемент компью- } \\
\text { тера }\end{array}$ & черная & \begin{tabular}{|l} 
Пласт- \\
маса
\end{tabular} & средний & 30,00 & нет & есть & есть & $\begin{array}{l}\text { прямоуголь- } \\
\text { ная }\end{array}$ & нет \\
\hline клавиатура2 & $\begin{array}{l}\text { клавиату- } \\
\text { ра }\end{array}$ & $\begin{array}{l}\text { элемент компью- } \\
\text { тера }\end{array}$ & белая & \begin{tabular}{|l|} 
Пласт- \\
маса \\
\end{tabular} & средний & 32,00 & нет & есть & есть & $\begin{array}{l}\text { прямоуголь- } \\
\text { ная }\end{array}$ & нет \\
\hline сумка1 & сумка & аксессуар & бежевая & кожа & большой & 41,00 & нет & нет & нет & $\begin{array}{l}\text { прямоуголь- } \\
\text { ная }\end{array}$ & нет \\
\hline сумка2 & сумка & аксессуар & черная & силикон & средний & 42,00 & нет & нет & нет & овальная & нет \\
\hline сумка3 & сумка & аксессуар & красная & кожзам & средний & 38,00 & нет & нет & нет & $\begin{array}{l}\begin{array}{l}\text { прямоуголь- } \\
\text { ная }\end{array} \\
\end{array}$ & нет \\
\hline монитор1 & монитор & $\begin{array}{l}\text { элемент компью- } \\
\text { тера }\end{array}$ & черный & \begin{tabular}{|l} 
Пласт- \\
маса
\end{tabular} & средний & 40,00 & есть & есть & есть & квадратная & нет \\
\hline монитор2 & монитор & $\begin{array}{l}\text { элемент компью- } \\
\text { тера }\end{array}$ & серый & \begin{tabular}{|l|} 
Пласт- \\
маса \\
\end{tabular} & средний & 37,00 & есть & есть & есть & квадратная & нет \\
\hline стул & стул & мебель & серый & метал & средний & 50,00 & нет & нет & нет & сложная & есть \\
\hline стол & стол & мебель & коричневый & $\begin{array}{l}\text { деревя- } \\
\text { ный }\end{array}$ & большой & 150,00 & нет & нет & нет & $\begin{array}{l}\text { прямоуголь- } \\
\text { ная }\end{array}$ & есть \\
\hline вещалка & вещалка & мебель & $\begin{array}{l}\text { светло корич- } \\
\text { невая } \\
\end{array}$ & $\begin{array}{l}\text { деревя- } \\
\text { ный }\end{array}$ & большая & 200,00 & нет & нет & нет & сложная & нет \\
\hline телесрон1 & телефон & средство связи & белый & \begin{tabular}{|l} 
Пласт- \\
маса
\end{tabular} & под руку & 7,00 & есть & есть & нет & \begin{tabular}{|l}
$\begin{array}{l}\text { прямоуголь- } \\
\text { ная }\end{array}$ \\
\end{tabular} & нет \\
\hline телефон2 & телефрон & средство связи & черный & \begin{tabular}{|l|} 
Пласт- \\
маса \\
\end{tabular} & под руку & 7,00 & есть & есть & нет & $\begin{array}{l}\text { прямоуголь- } \\
\text { ная }\end{array}$ & нет \\
\hline телефон3 & телефон & средство связи & серый & \begin{tabular}{|l|} 
Пласт- \\
маса
\end{tabular} & под руку & 8,00 & есть & есть & нет & $\begin{array}{l}\text { прямоуголь- } \\
\text { ная }\end{array}$ & нет \\
\hline $\begin{array}{l}\text { мяч пИнг- } \\
\text { понг }\end{array}$ & мЯч & спорт инвентарь & белый & $\begin{array}{l}\text { пластма- } \\
\text { са }\end{array}$ & $\begin{array}{l}\text { малень- } \\
\text { кий }\end{array}$ & 20,00 & нет & нет & нет & круглая & нет \\
\hline мяч тенис & мяч & спорт инвентарь & желтый & резина & средний & 25,00 & нет & нет & нет & круглая & нет \\
\hline мяч футбол & Мяч & спорт инвентарь & черно-белый & кожа & большой & 24,00 & нет & нет & нет & круглая & нет \\
\hline $\begin{array}{l}\text { мяч баскет- } \\
\text { бол }\end{array}$ & Мяч & спорт инвентарь & оранжевый & резина & большой & 30,00 & нет & нет & нет & круглая & нет \\
\hline
\end{tabular}


Структура таблицы исходных данных 1 соответствует требованиям системы «Эйлос», представленным в Help на рисунке 2:

О) Помощь по режиму 2.3.2.2 для случая Ехсеl-файлов исходных данных

Режим 2.3.2.2: Чниверсальный программный интерфейс импорта данных из внешней базы данных "Inp_data.xIs" в системy "Эйдос-x++" и формализации предметной области.

- Данный программный интерфейс обеспечивает автоматическое формирование классификационных и описательных шкал и градаций, а также обучающей и распознаваемой выборки, Т. е. формализацию предметной области, на основе XLS или XLSX-файла с исходными данными при веденного ниже стандарта.

- Файл исходных данных должен иметь имя: INP_DATA.XLS или INP_DATA.XLSX и может бьпь получен в Ехсеl-2003(2007-2010), а файл распознаваемой выборки имя: INP_RASP.XLS или INP_RASP.XLSX. Файлы INP_DATA.XLS (INP_DATA.XLSX) и INP_RASP.XLS или INP_RASP.XLSX] должны находиться в папке /AIDOS-X/AID_DATA/Inp_data/ и имеют совершенно одинаковую структуру.

- 1-я строка этого файла должна содержать наименования колонок на любом языке, в т. ч. и русском. Эти наименования должны быпь во всех колонках, при этом объединение ячеек и переносы слов не допускаются. Желательно, чтобы эти наименования были не очень длинными,

т.К. К ним еще бцдит добавляться интервальные числовые или текстовые значения.

- Каждая строка этого файла, начиная со 2-й, содержит данные об одном объекте обучающей выборки. Если Ехсеl-2003, в листе может быпь до 65536 строк и до 256 колонок. В листе Exсеl-2007(2010) возможно до 1048576 строк и 16384 колонок.

- Столбцы, начиная Со 2-го, являются классификационными и описательными шкалами и могут бьпь текстового (номинального) или числового типа (с десятичными знаками после запятой).

- Столбцу присваивается числовой тип, если все значения его ячеек числового типа. Если хотя бы одно значение является текстовым (не числом, в Т.4. пробелом], то столбцу присваивается текстовый тип. Это означает, что нули должны бьть указаны нулями, а не пробелами. - 1-й столбец содержит наименование источника данных длиной до 255 символов, но желательно, чтобы эти наименования были не очень длинными.

- Столбцы со 2-го по N-й являются Классификационными шкалами (выходными параметрами) и содержат данные о классах [будущих состояни ях объекта чправления), к которым принадлежат объекты обучающей выборки.

- Столбцы с $\mathrm{N}+1$ по последний являются описательными шкалами [факторами] и содержат данные о признаках [значениях факторов], характеризующих объекты обучающей выборки.

- В результате работы режима формируется файл INP_NAME.TXT стандарта MS DOS (кириллица), в котором наименования классификационных и описательных шкал являются СТРОКАМИ. Система формирует классификационные и описательные шкалы и градации. Дляэтого в каждом числовом столбце система находит минимальное и максимальное числовые значения и формирует заданное количество числовых интервалов, после чего числовые значения заменяются их интервальными значениями. В текстовых столбцах система находит уникальные текстовые значения. Каждое ЧНИКАЛЬНОЕ интервальное числовое или текстовое значение считается градацией классификационной или описательной шкалы, характеризующей объект. [ ик использованием генерируется обучающая выборка, каждый объект которой соответствует одной строке файла исходных данных NP_DATA и содержит коды классов, соответствующие фактам совпадения числовых или уникальных текстовых значений классов с градациями классификационных шкал и коды признаков, соответствующие фактам совпадения числовых или уникальных текстовых значений признаков с градациями описательных шкал.

- Распознаваемая выборка формируется на основе файла INP_RASP аналогично, за исключением того, что классификационные и описательные шкалы и градации не создаются, а используются ранее созданные в модели, и базы распознаваемой выборки могут не включать коды классов, если столбцы классов в файле INP_RASP были пустыми. Структура файла INP_RASP должна быть такая же, как INP_DATA, T.e. oHи должны ПОЛНОСТЬЮ совпадать по столбцам, но могут иметь разное количество строк.

Принцип организации таблицы исходных данных

\begin{tabular}{|c|c|c|c|c|c|c|}
\hline $\begin{array}{l}\text { Наименование объекта } \\
\text { обучающей выборки }\end{array}$ & $\begin{array}{l}\text { Наименование 1-й } \\
\text { классификационной } \\
\text { шкалы }\end{array}$ & $\begin{array}{l}\text { Наименование 2-й } \\
\text { классификационной } \\
\text { шкалы }\end{array}$ & ... & $\begin{array}{l}\text { Наименование 1-й } \\
\text { описательной } \\
\text { шкапы }\end{array}$ & $\begin{array}{l}\text { Наименование 2-й } \\
\text { описательной } \\
\text { шкалы }\end{array}$ & $\ldots$ \\
\hline 1-й объект обучающей выборки & Значение показателя & Значение показателя & $\ldots$ & $\begin{array}{l}\text { 3начение } \\
\text { показателя }\end{array}$ & $\begin{array}{l}\text { 3начение } \\
\text { показателя }\end{array}$ & $\ldots$ \\
\hline 2-й объект обучающей выборки & Значение показателя & Значение показателя & ... & $\begin{array}{l}\text { Значение } \\
\text { показателя }\end{array}$ & $\begin{array}{l}\text { Значение } \\
\text { показателя }\end{array}$ & ... \\
\hline$\ldots$ & $\ldots$ & $\ldots$ & $\ldots$ & $\ldots$ & $\ldots$ & $\ldots$ \\
\hline
\end{tabular}

Рисунок 2. Неlp программного интерфейса ввода данных из внешних баз данных системы «Эйдос»

Каждая строка таблицы 1 содержит информацию об одном физическом объекте обучающей выборки. Классификационные шкалы выделены желтым фоном и представляют собой способы группировки объектов для формирования классов. Классы представляют собой градации классификационных кал. Кажндый физический объект обучающей выборки включа- 
ет два логических объекта, относящихся к конкретным и обобщающим классам. Поэтому получается, что 20 физических объектов в таблице 1 представлены в форме 40 логических объектов.

На рисунке 3 представлены классификационные шкалы и градации, а на рисунке 4 - описательные шкалы и градации:

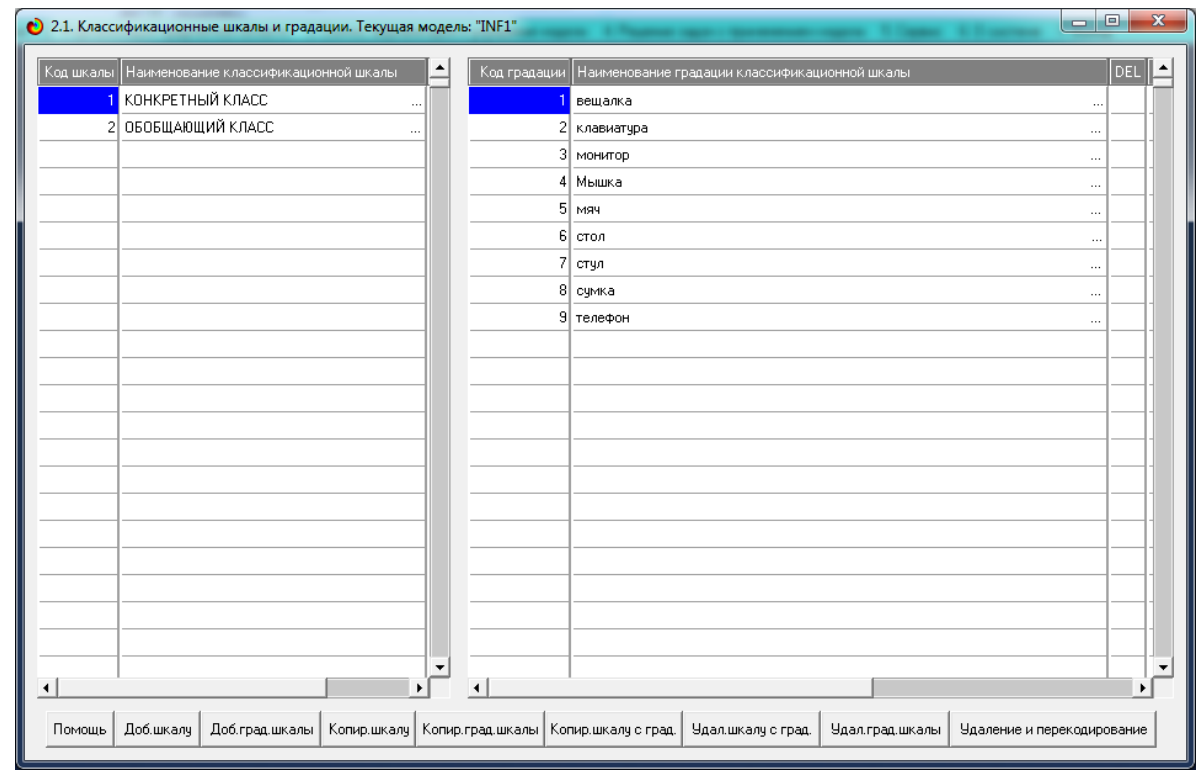

Рисунок 3. Классификационные шкалы и градации

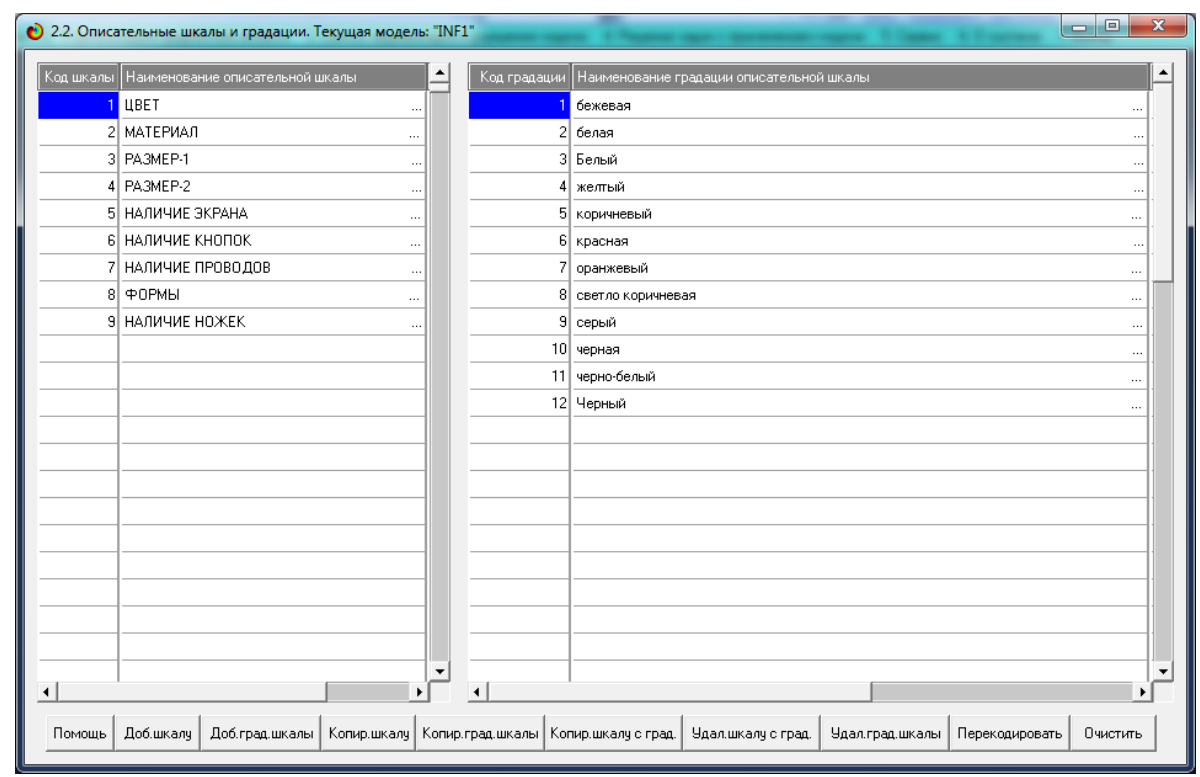

Рисунок 4. Описательные шкалы и градации

На рисунке 5 представлена обучающая выборка, представляющая собой нормализованную с помощью справочников классификационных и 
описательных шкал и градаций (рисунки 3. 4) таблицу исходных данных (таблица 1):

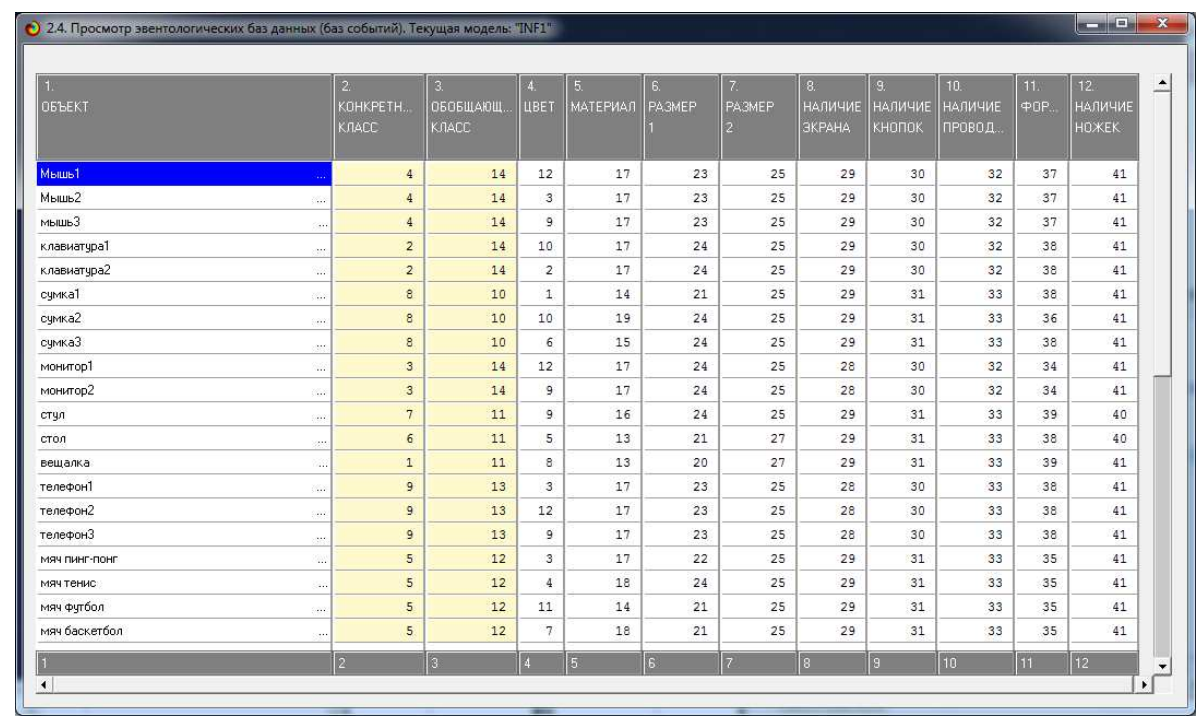

Рисунок 5. Обучающая выборка

Синтез и верификация моделей осуществляется в режиме 3.5 (рисунок 6):

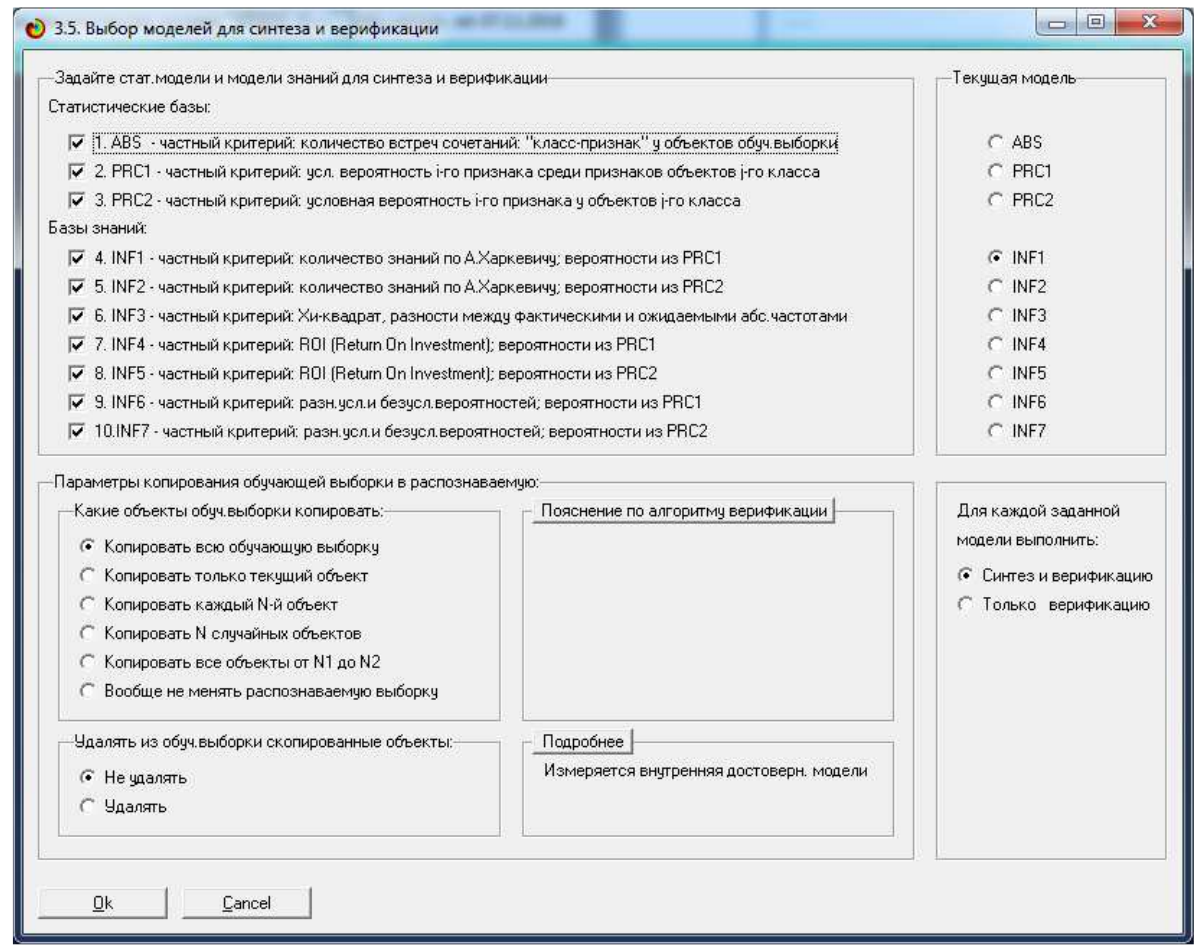

Рисунок 6. Экранная форма режима 3.5 системы «Эйдос»

На рисунке 7 приведена экранная форма режима 3.5 с отображением стадии исполнения синтеза и верификации моделей: 


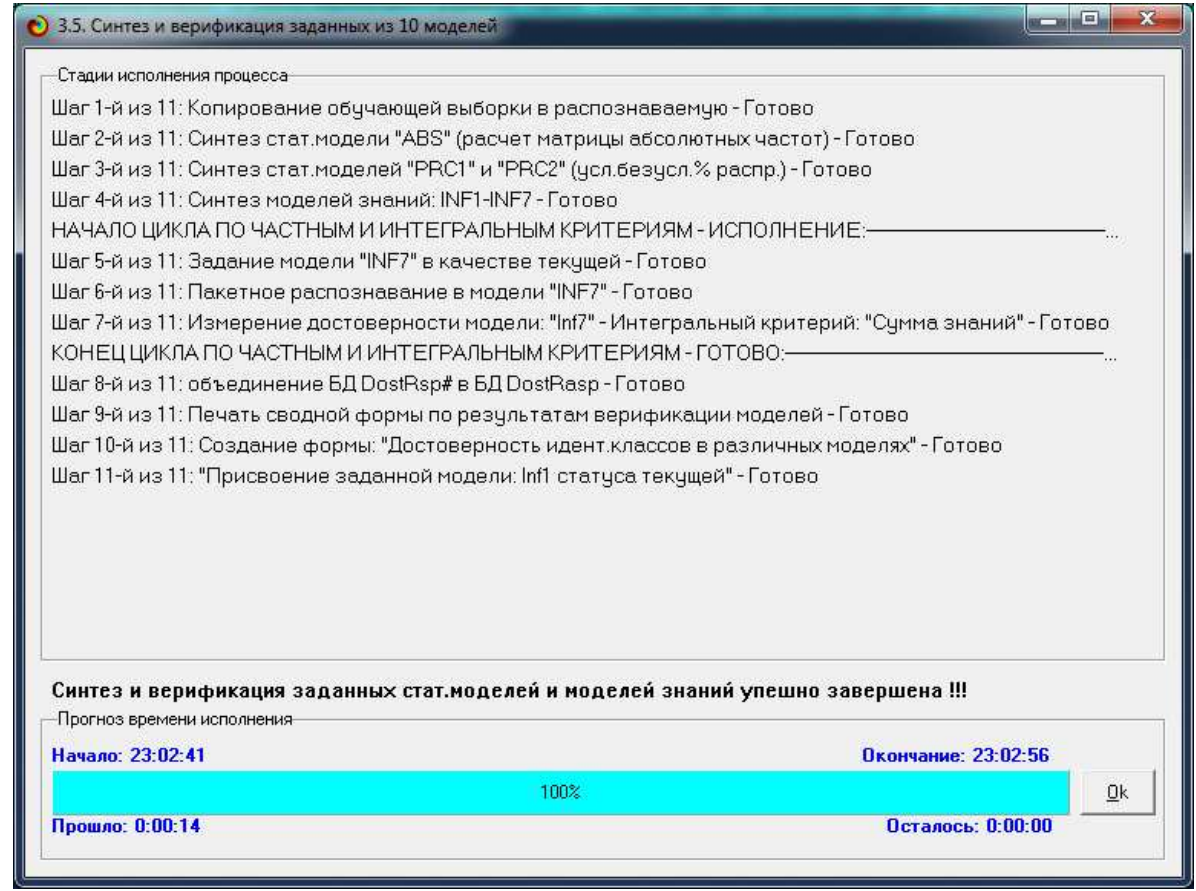

Рисунок 7. Экранная форма режима 3.5 с отображением стадии исполнения синтеза и верификации моделей

На рисунке 8 приведена выходная экранная форма с отображением результатов верификации моделей с применением классической F-меры Ван Ризбергена и L-меры проф.Е.В.Луценко, которая представляет собой ее нечеткое мультиклассовое обобщение:

\begin{tabular}{|c|c|c|c|c|c|c|c|c|c|c|c|c|c|c|c|c|}
\hline \multicolumn{7}{|c|}{ O 4.13.6. Обобщ,форма по достов.моделей при разн.интт.крит. Техущая модель: 'TNF1" } & \multirow{2}{*}{ Toнность } & \multicolumn{2}{|l|}{ 18 } & \multicolumn{6}{|c|}{ 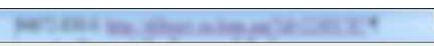 } & $(0,0$ \\
\hline 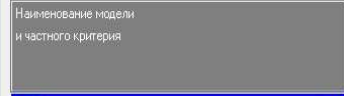 & Иитегральный.... & \begin{tabular}{|l|} 
Boero \\
nornueckux \\
ofrektoo \\
Ebropkn \\
\end{tabular} & 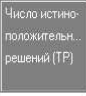 & 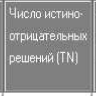 & 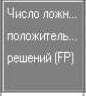 & \begin{tabular}{|l|} 
4... \\
or.. \\
pe..
\end{tabular} & & 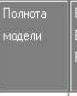 & 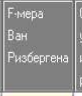 & 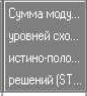 & 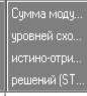 & 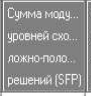 & $\begin{array}{l}E y . \\
\text { yp.. } \\
n 0 .\end{array}$ & 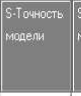 & 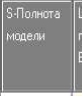 & $\begin{array}{l}\text { Limepa. } \\
\text { npop. } \\
\text { E. B. Iyuer. }\end{array}$ \\
\hline & Корреляиия аб... & 40 & 40 & 16 & 224 & & 0.152 & 1.000 & 0.263 & 35.108 & 2.481 & 63.448 & & 0.356 & 1.000 & 0.525 \\
\hline 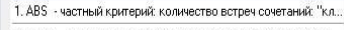 & Сумmа абс част.. & 40 & 40 & 3 & 237 & & 0.144 & 1.000 & 0.252 & 21.792 & & 49.958 & & 0.304 & 1.000 & 0.466 \\
\hline 2. PRC1 - часттый критерий. усл. вероятность ігго признака а.... & Корреляиия ус... & 40 & 40 & 16 & 224 & & 0.152 & 1.000 & 0.263 & 35.108 & 2.481 & 63.448 & & 0.356 & 1.000 & 0.525 \\
\hline 2. PRC1 - частный критерий. усл. веровтность ігго признака а.... & Cynма услотн.... & 40 & 40 & 3 & 237 & & 0.144 & 1.000 & 0.252 & 33.005 & & 95.656 & & 0.257 & 1.000 & 0.408 \\
\hline 3. РАС2 - чзстный критерий. условная вероятность іго призн... & Корреляиия ус... & 40 & 40 & 16 & 224 & & 0.152 & 1.000 & 0.263 & 35.108 & 2.481 & 63.448 & & 0.356 & 1.000 & 0.525 \\
\hline 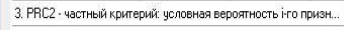 & Суммна услотн.... & 40 & 40 & 3 & 237 & & 0.144 & 1.000 & 0.252 & 33.005 & & 95.656 & & 0.257 & 1.000 & 0.408 \\
\hline 4. INF1 - частный критерий. количество знаний по А.Харкевичи.. & Семэнтиесский. & 40 & 40 & 184 & 56 & & 0.417 & 1.000 & 0.588 & 23.962 & 40.343 & 10.323 & & 0.699 & 1.000 & 0.823 \\
\hline 4. INF1- частный критерий: колниество Знаний ио А.Харкевин.. & Сумма Знаний... .. & 40 & 40 & 38 & 202 & & 0.165 & 1.000 & 0.284 & 18.601 & 2.094 & 23.511 & & 0.442 & 1.000 & 0.613 \\
\hline 5. INF2- частный критерий. колниество зняний по.А.Харкеешич.. & Сематтиесский. & 40 & 40 & 184 & 56 & & 0.417 & 1.000 & 0.588 & 23.962 & 40.343 & 10.323 & & 0.699 & 1.000 & 0.823 \\
\hline 5. INF2- частный критерий. количество энаний по А.Х.аркевин.. & Сумпа знанй ... . . & 40 & 40 & 38 & 202 & & 0.165 & 1.000 & 0.284 & 18.601 & 2.094 & 23.511 & & 0.442 & 1.000 & 0.613 \\
\hline 6. INF3 - частный критерий: Хи-кварарт, разности межау факт... & Сематтиеский. & 40 & 40 & 162 & 78 & & 0.339 & 1.000 & 0.506 & 31.624 & 54.388 & 17.219 & & 0.647 & 1.000 & 0.786 . \\
\hline 6. INF3 - частный критерийі Хинкенарат, разнности межау факт... & Сумма знаний ... & 40 & 40 & 162 & 78 & & 0.339 & 1.000 & 0.506 & 24.853 & 36.387 & 11.534 & & 0.683 & 1.000 & 0.812 \\
\hline 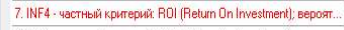 & Cематтиеский. & 40 & 40 & 201 & 39 & & 0.506 & 1.000 & 0.672 & 24.120 & 50.166 & 6.138 & & 0.797 & 1.000 & 0.887 \\
\hline 7. INF4 - частный критерий. ROI (Retur On Investment); вероят... & Сумма знаний... .. . & 40 & 40 & 23 & 217 & & 0.156 & 1.000 & 0.269 & 9.573 & 0.202 & 8.275 & & 0.536 & 1.000 & 0.698 \\
\hline 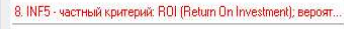 & Сематтиеский. & 40 & 40 & 201 & 39 & & 0.506 & 1.000 & 0.672 & 24.120 & 50.166 & 6.138 & & 0.797 & 1.000 & 0.887 \\
\hline 8. INF5 - частный критерий: ROl (Retum On Investment): вероят... & Сумма знаний ... & 40 & 40 & 23 & 217 & & 0.156 & 1.000 & 0.269 & 9.573 & 0.202 & 8.275 & & 0.536 & 1.000 & 0.698 \\
\hline 9. INF6 - частный критерий. разн.усл.и безусл.вероятностей.... & Семантинеский. & 40 & 40 & 137 & 103 & & 0.280 & 1.000 & 0.437 & 29.818 & 23.516 & 23.346 & & 0.561 & 1.000 & 0.719 \\
\hline 9. INF6- частный критерий. разн.усл.и безусл.вероятностейі... & Сумма знаний... . . & 40 & 40 & 22 & 218 & & 0.155 & 1.000 & 0.268 & 20.300 & 1.753 & 37.071 & & 0.354 & 1.000 & 0.523 \\
\hline 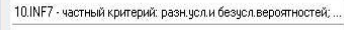 & Семантиесский. & 40 & 40 & 137 & 103 & & 0.280 & 1.000 & 0.437 & 29.818 & 23.516 & 23.346 & & 0.561 & 1.000 & 0.719 \\
\hline 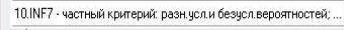 & Сумма знаний... & 40 & 40 & 26 & 214 & & 0.157 & 1.000 & 0.272 & 20.300 & 1.753 & 37.071 & & 0.354 & 1.000 & 0.523 . \\
\hline 1 & & & & & & & & & & & & & & & & . \\
\hline
\end{tabular}

Рисунок 8. Выходная экранная форма с отображением результатов верификации моделей с применением классической F-меры Ван Ризбергена и L-меры проф.Е.В.Луценко, которая представляет собой ее нечеткое мультиклассовое обобщение 
Из сравнения значений F-меры и L-меры мы видим, что L-мера имеет большие значения. Это обусловлено тем, что при истинных результатах классификации (как идентификации, так и неидентификации), уровень сходства-различия выше, чем при ложных результатах классификации, в классической F-мере это не учитывается.

Это наглядно видно на форме, представленной на рисунке 9:

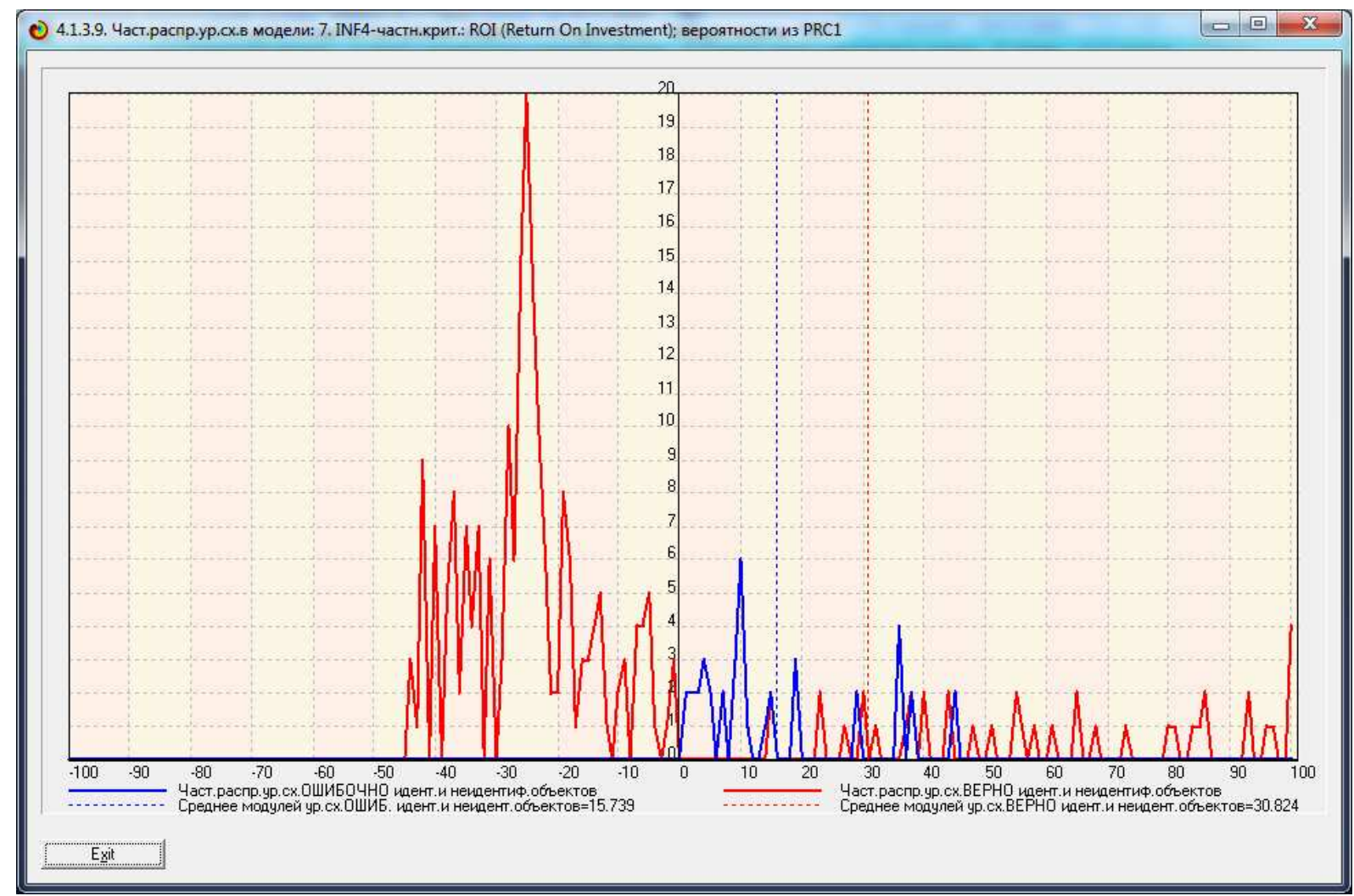

Рисунок 9. Частотное распределение уровней сходства верно и ошибочно идентифицированных и неидентифицированных объектов обучающей выборки при их сравннии со всеми классами в наиболее достоверной модели INF4

Из рисунка 9 видно, что:

-в модели INF4 встречаются только положительные ошибочные решения;

- при ошибочных решениях (синий цвет графика) уровень сходства объектов с классами не превосходит 45\%, а при истинных он достигает, $100 \%$; 
- при отрицательных решениях в модели INF4 уровень различия по модулю значительно выше, чем сходства при положительных.

Поэтому если при положительных решениях игнорировать те из из них, которые с уровнем сходства ниже 45\%, то модель вообще не будет иметь ложных решений. При использовании классической F-меры Ван Ризбергена аналогичная возможнность вообце отсутствует в принциne.

На рисунке 10 приведен Help режима вывода результатов верификации моделей.

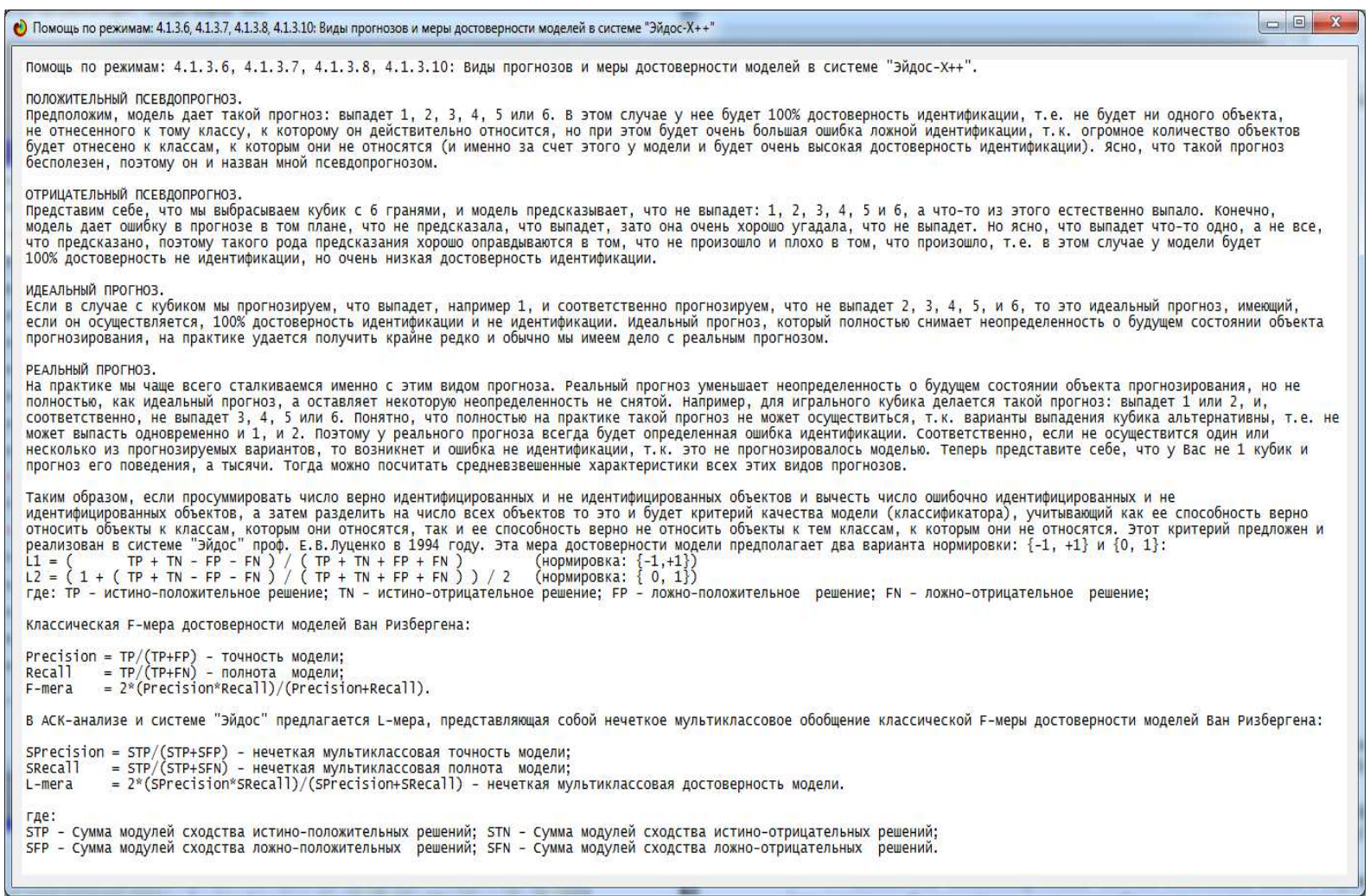

Рисунок 10. Help режима 4.1.3.6 системы «Эйдос»

В соответствии с порядком преобразования данных в информацию, а ее в знания, в соответствии с которым построена система «Эйдос» (рисунок 11), наиболее достоверная модель делается текущей и в ней решаются все задачи АСК-анализа:

- классификации, прогнозирования, идентификации, диагностики, распознавания; 
- поддержки принятия решений;

- исследования моделируемой предметной области путем исследования ее модели:

Последовательность обработки данных, информации и знаний в системе «Эйдос-Х++»

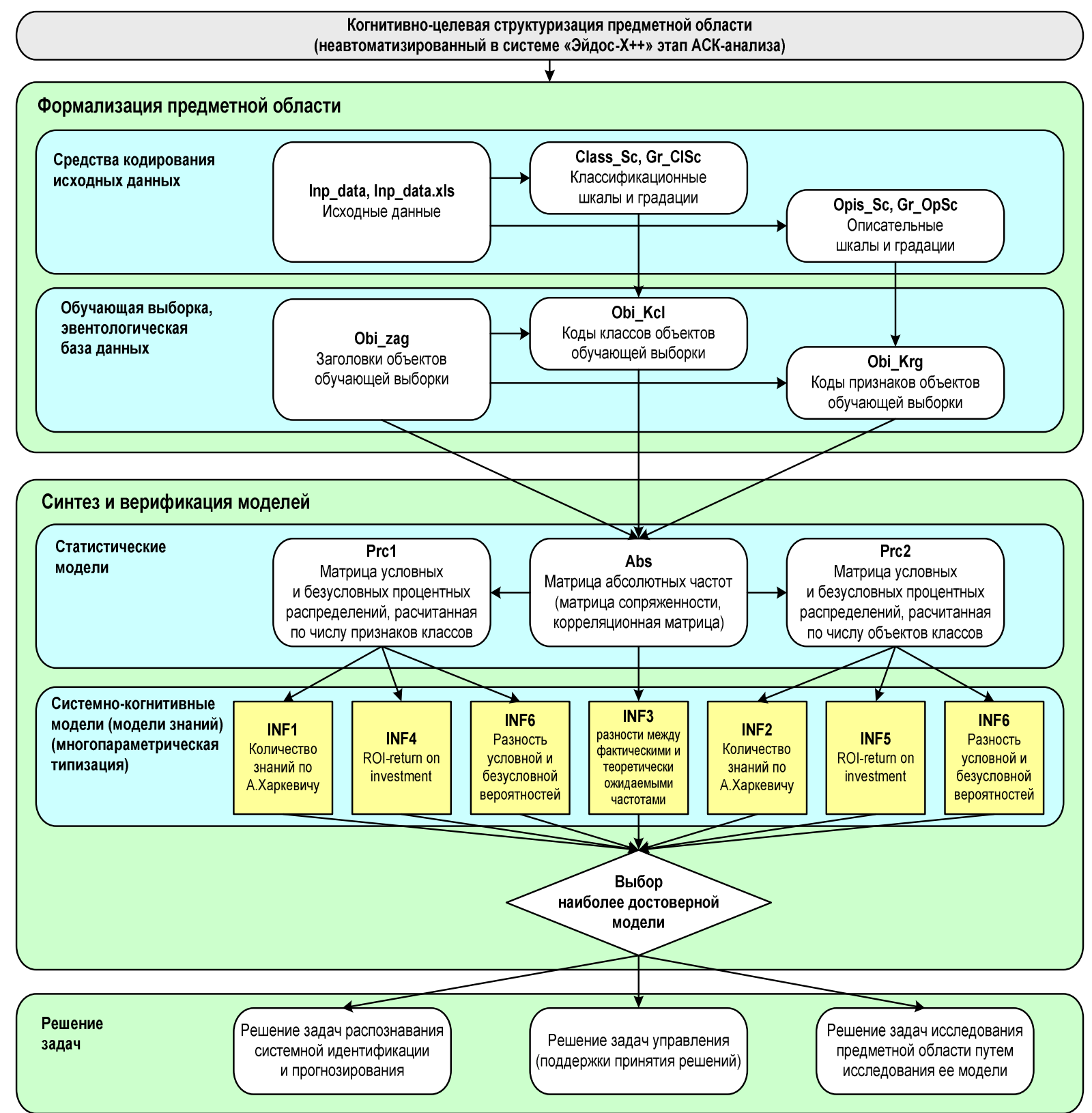

Рисунок 11. Порядок преобразования данных в информацию, а ее в знания, в соответствии с которым построена система «Эйдос»

Различные модели отличаются частными критериями знаний [9].

В соответствии с этой схемой и рисунком 8 установим в качестве текущей модель INF4 (рисунок 12): 
(2) 5.6. Выбрать модель и сделать ее текущей

Задайте текущую стат.модель или модель знаний

Статистические базы:

C 1. АBS - частный критерий: количество встреч сочетаний: "Класс-признак" у объектов обуч.выборки

C 2. PRC1 - частный критерий: усл. вероятность і-го признака среди признаков объектов j-го класса

C. 3. PRC2 - частный критерий: условная вероятность і-го признака у объектов і-го класса

Базы знаний:

C 4. INF1 - частный критерий: количество знаний по А.Харкевичу; вероятности из PRC1

C 5. INF2 - частный критерий: количество знаний по АХХаркевичу; вероятности из PRC2

C. INF3 - частный критерий: Хи-квадрат, разности между фактическими и ожидаемыми абс. частотами

c. 7. INF4 - частный критерий: ROі (Retum On Investment): вероятности из PRC1

8. INF5 - частный критерий: ROI (Return On Investment); вероятности из PRC2

C 9. INF6 - частный критерий: разн.усл.и безусл.вероятностей; вероятности из PRC1

10.INF7 - частный критерий: разн.усл.и безусл.вероятностей; вероятности из PRC2

Как задавать параметры синтеза моделей

В качестве текущей можно задать любую из ранее расчитанных в режимах $3.1,3.2,3.3$ или 3.4 стат. моделей и моделей знаний, но до исследования достоверности моделей в режиме 3.5 рекомеңдуется выбрать в качестве текущей базу знаний INF1. Смысл моделей знаний, применяемых в системе "Эйдос-X++" раскрып в публикацияк, размещенных по адресам: http://c.kubagro.ru/aidos/index.htm, http://www. twirpx.com/file/793311/

$\underline{\underline{Q} \mathrm{k}}$ Cancel

5.6. Выбрать модель и сделать ее текущей

Стадии исполнения процесса

ОПЕРАЦИЯ: ПРИСВОЕНИЕ МОДЕЛИ "INF4" СТАТЧСА ТЕКЧЩЕЙ МОДЕЛИ:

1/7: Копирование в массивы итоговых строки столбцов текущей модели -Готово

2/7: Перенос информации из текущей модели в базы классов: Classes и Gr_ClSc-Готово

3/7: Перенос информации из текцщей модели в базы признаков: Attributes и Gr_OpSc-Готово

4/7: Расчет значимости класс.и опис.шкал-Сброс сумматоров - Готово

5/7: Расчет значимости класс.и опис.шкал-Накопление данных-Готово

6/7: Расчет значимости класс. и опис.шкал-Дорасчет -Готово

7/7: Запись информации о текущей модели -Готово

Выбор модели знании́ "INF4" в качестве текущеи́ прошел успешно!!!

Прогноз времени исполнения

Начало: 23:40:40

Окончание: 23:40:42

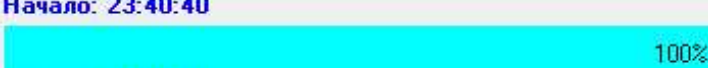

Прошло: 0:00:02

Рисунок 12. Присвоение наиболее достоверной модели статуса текущей модели

Пакетное распознавание в наиболее достоверной модели INF4 (рисунок 13): 
(О) 4.1.2. Пакетное раслознавание. Текущая модель: "INF4"

Стадии исполнения процесса

ОПЕРАЦИЯ: ПАКЕТНОЕ РАСПОЗНАВАНИЕ В ТЕКЧЩЕЙ МОДЕЛИ "INF4":

1/11: Распознавание (идентификация) 20-го объекта обучающей выборки из 20 - Готово

2/11: Исследование распределений уровней сходства верно и ошиб. идент. объектов - Готово

3/11: Создание сжатых полных форм результатов распознавания по 2-му интегр.крит. - Готово

4/11: Создание подробной наглядной формы: "Объект-классы". Инт.крит.-корреляция - Готово

5/11: Создание подробной наглядной формы: "Объект-классы". Инт.крит.-сумма инф. -Готово

6/11: Создание итоговой наглядной формы: "Объект-класс". Инт.крит -корреляция -Готово

7/11: Создание итоговой наглядной формы: "Объект-класс". Инт.крит.-сумма инф. -Готово

8/11: Создание подробной наглядной формы: "Класс-объекты". Инт.крит.-корреляция -Готово

9/11: Создание подробной наглядной формы: "Класс-объекты". Инт. крит.-сумма инф. -Готово

10/11: Создание итоговой наглядной формы: "Класс-объекты". Инт. крит.-корреляция -Готово

11/11: Создание итоговой наглядной формы: "Класс-объекты". Инт.крит.-сумма инф. -Готово

ПАКЕТНОЕ РАСПОЗНАВАНИЕ ОБЪЕКТОВ РАСПОЗНАВАЕМОЙ ВЫБОРКИ ЗАВЕРШЕНО ЧСПЕШНО !

Прогноз времени исполнения

Начало: 23:43:03

Окончание: 23:43:04

Прошло: 0:00:01

$103 \%$

Осталось: 0:00:00

Рисунок 13. Экранная форма, отражающая процесс пакетного распознавания в наиболее достоверной модели INF4 (рисунок 13):

На рисунке 14 приведен фрагмент меню системы «Эйдос», на котором показаны режимы отображения результатов распознавания:

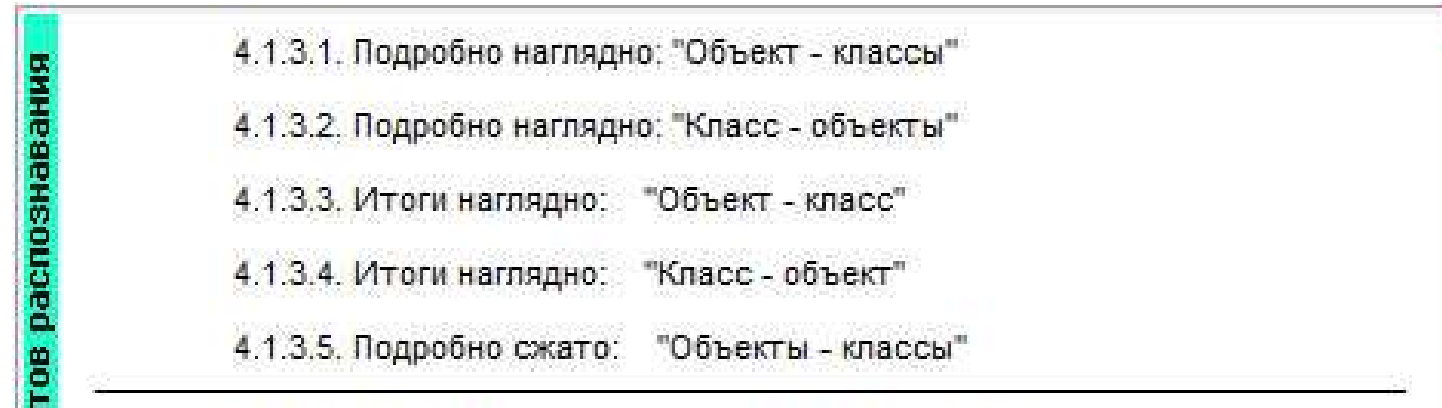

4.1.3.6. Обобщ. форма по достов.моделей при разных интегральных крит.

4.1.3.7. Обобщ. стат.анализ результатов идент. по моделям и инт.крит.

4.1.3.8. Стат.анализ результ. идент, по классам, моделям и инт.крит.

4.1.3.9. Достоверность идент.объектов при разных моделях и инт.крит.

4.1.3.10.Достоверность идент.классов при разных моделях и инт.крит.

4.1.3.11.Распределения уровн.сходства при разных моделях и инт.крит.

Рисунок 14. Фрагмент меню системы «Эйдос», на котором показаны режимы отображения результатов распознавания
} 
На рисунке 15 мы видим один из этих результатов классификации, отображаемых в режиме 4.1.3.2:

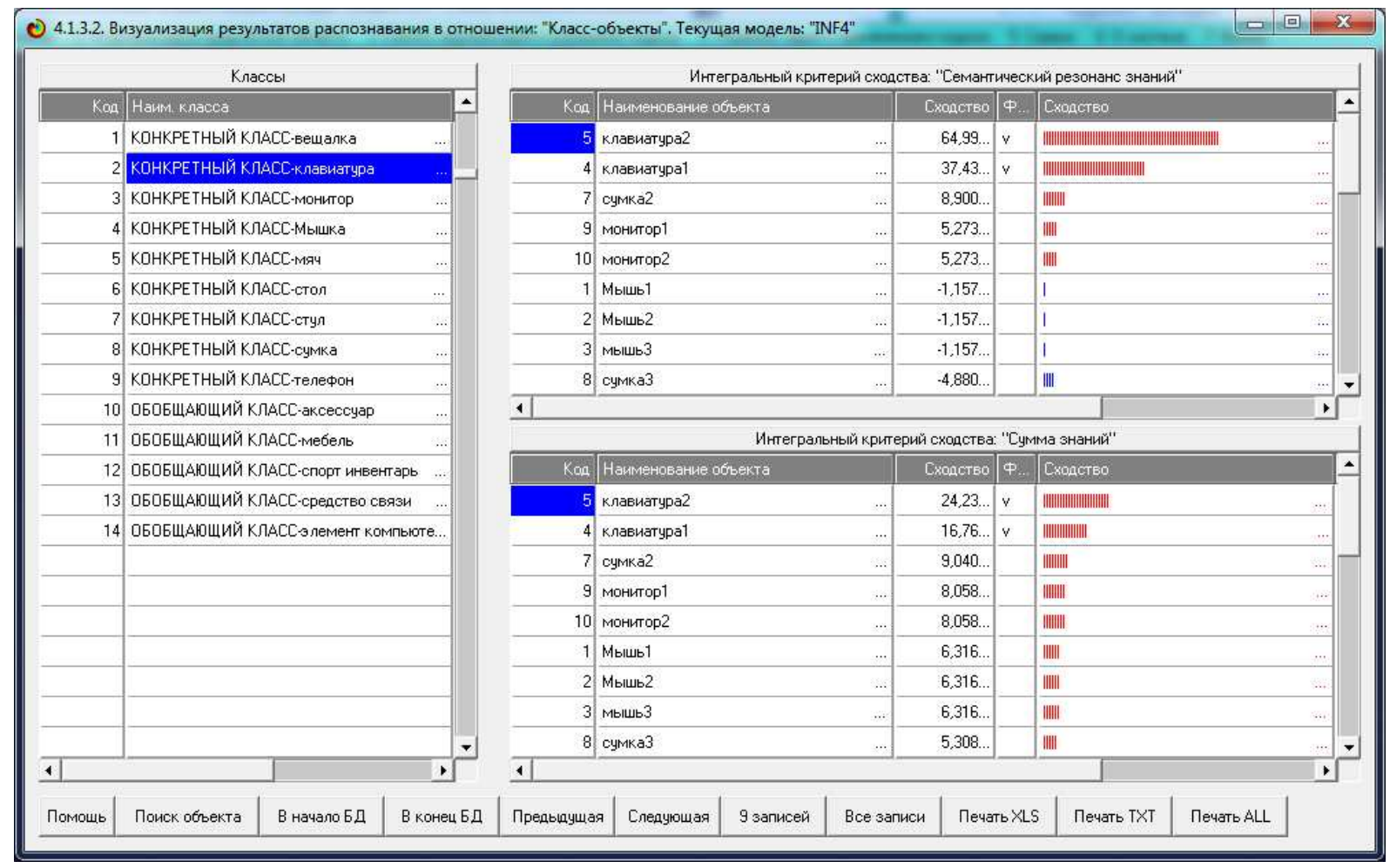

Рисунок 15. Одна из выходных форм система «Эйдос» с отображением результатов классификации в наиболее достоверной модели INF4

На рисунке 15 мы видим три ложно-положительных решения, но мы и видим также, что уровни сходства объектов с классом при этих решениях значительно (в разы) меньше, чем при истино-положительных решениях (отмечены «птичкой»). Из предыдущего изложения ясно, что F-мера не учитывает этого существенного обстоятельства и этот ее недостаток преодолевается предложенной в данной работе L-мерой.

На рисунках 16 выходные формы по результатам классификации с расчетом F-меры и L-меры для классов и объектов тестовой выборки.

Необходимо отметить также, что все выходные экранные формы в системе «Эйдос» просто визуализируют в окнах специально созданные выходные базы данных DBF-стандарта, которые открываются всеми версиями MS Excel и практически готовы для печати. 

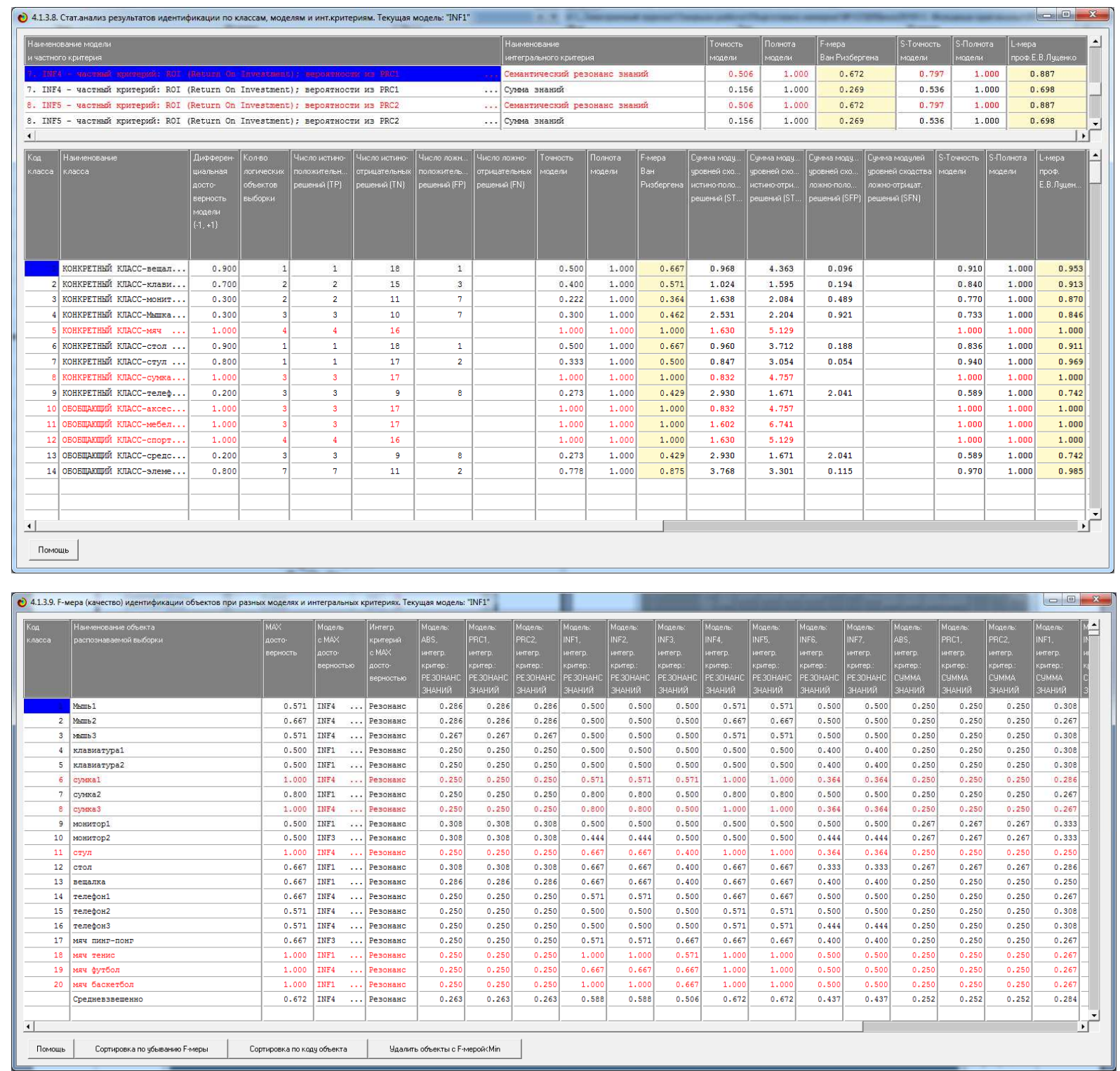

Рисунок 16. Выходные экранные формы по результатам классификации с расчетом F-меры и L-меры для классов и объектов тестовой выборки

\section{Выводы}

Классическая количественная мера достоверности моделей: F-мера Ван Ризбергена основана на подсчете суммарного количества верно и ошибочно классифицированных и не классифицированных объектов обучающей выборки. В мультиклассовых системах классификации объект может одновременно относится ко многим классам. Соответственно при синтезе модели его описание используется для формирования обобщенных 
образов многих классов, к которым он относится. При использовании модели для классификации определяется степень сходства-различия объекта со всеми классами, причем истинно-положительным решением может являться принадлежность объекта сразу к нескольким классам. В результате такой классификации получается, что объект не просто правильно или ошибочно относится или не относится к различным классам, как в классической F-мере, но правильно или ошибочно относится или не относится к ним в различной степени. Однако классическая F-мера не учитывает того, что объект может фактически одновременно относится ко многим классам (мультиклассовость) и того, что в результате классификации может быть получена различная степень сходства-различия объекта с классами (нечеткость). На численных примерах автором установлено, что при истинноположительных и истинно-отрицательных решениях модуль сходстваразличия объекта с классами значительно выше, чем при ложноположительных и ложно-отрицательных решениях. Поэтому было бы рационально в мере достоверности модели учитывать не просто сам факт истинно или ложно положительного или отрицательного решения, но и учитывать степень уверенности классификатора в этих решениях. В интеллектуальной системе «Эйдос», которая является программным инструментарием автоматизированного системно-когнитивного анализа (АСК-анализ), изначально используется предложенная их разработчиком мера достоверности моделей, по сути являющаяся нечетким мультиклассовым обобщением классической F-меры (предлагается называть еe L-мерой). B данной статье L-мера описана математически и ее применение продемонстрировано на простом численном примере.

Предлагаемые технологии синтеза и верификации моделей могут быть использованы при создании и применении адаптивных интеллектуальных измерительных систем [10], а также разработке нечетких муль- 
тиклассовых обобщений других мер достоверности моделей, которые довольно разнообразны и многочисленны [6].

\section{Литература}

1. Сайт: http://bazhenov.me/blog/2012/07/21/classification-performanceevaluation.html

2. Сайт: https://habrahabr.ru/post/228963/

3. Луценко Е.В. Универсальная когнитивная аналитическая система «Эйдос". Монография (научное издание). - Краснодар, КубГАУ. 2014. - 600 с. ISBN 978-594672-830-0. http://elibrary.ru/item.asp?id=22401787

4. Орлов А.И., Луценко Е.В. Системная нечеткая интервальная математика. Монография (научное издание). - Краснодар, КубГАУ. 2014. - 600 с. ISBN 978-5-94672757-0. http://elibrary.ru/item.asp?id=21358220

5. Луценко Е.В. Автоматизированный системно-когнитивный анализ в управлении активными объектами (системная теория информации и ее применение в исследовании экономических, социально-психологических, технологических и организационно-технических систем): Монография (научное издание). - Краснодар: КубГАУ. 2002. 605 c. http://elibrary.ru/item.asp?id=18632909

6. Амелькин С.А. Оценка эффективности рекомендательных систем. http://rcdl.ru/doc/2012/paper44.pdf

7. Шевелев О.Г. Методы автоматической классификации текстов на естественном языке: Учебное пособие. Томск: ТМЛ-Пресс, 2007. - 144c.

8. Луценко Е.В. Теоретические основы и технология адаптивного семантического анализа в поддержке принятия решений (на примере универсальной автоматизированной системы распознавания образов "ЭЙДОС-5.1"). - Краснодар: КЮИ МВД РФ, 1996. - 280c. http://elibrary.ru/item.asp?id=21745340

9. Луценко Е.В. Метризация измерительных шкал различных типов и совместная сопоставимая количественная обработка разнородных факторов в системнокогнитивном анализе и системе «Эйдос» / Е.В. Луценко // Политематический сетевой электронный научный журнал Кубанского государственного аграрного университета (Научный журнал КубГАУ) [Электронный ресурс]. - Краснодар: КубГАУ, 2013. №08(092). С. 859 - 883. - IDA [article ID]: 0921308058. - Режим доступа: http://ej.kubagro.ru/2013/08/pdf/58.pdf, 1,562 у.П.л.

10. Луценко Е.В. Синтез адаптивных интеллектуальных измерительных систем с применением АСК-анализа и системы «Эйдос» и системная идентификация в эконометрике, биометрии, экологии, педагогике, психологии и медицине / Е.В. Луценко // Политематический сетевой электронный научный журнал Кубанского государственного аграрного университета (Научный журнал КубГАУ) [Электронный ресурс]. - Краснодар: КубГАУ, 2016. - №02(116). С. 1 - 60. - IDA [article ID]: 1161602001. - Режим доступа: http://ej.kubagro.ru/2016/02/pdf/01.pdf, 3,75 у.п.л.

11. https://yandex.ru/search/?msid=1478655999.15495.22884.13159\&text=коэффицие нты\%20эмерджентности\%20Хартли\%20\%20Харкевича\&lr=35

12. Луценко Е.В. Количественные меры возрастания эмерджентности в процессе эволюции систем (в рамках системной теории информации) / Е.В. Луценко // Политематический сетевой электронный научный журнал Кубанского государственного аграрного университета (Научный журнал КубГАУ) [Электронный ресурс]. - Краснодар: КубГАУ, 2006. - №05(021). С. 355 - 374. - Шифр Информрегистра: 0420600012\0089, 
IDA [article ID]: 0210605031. - Режим доступа: http://ej.kubagro.ru/2006/05/pdf/31.pdf, 1,25 у.п.л.

13. Луценко Е.В. Обобщенный коэффициент эмерджентности Хартли как количественная мера синергетического эффекта объединения булеанов в системном обобщении теории множеств / Е.В. Луценко // Политематический сетевой электронный научный журнал Кубанского государственного аграрного университета (Научный журнал КубГАУ) [Электронный ресурс]. - Краснодар: КубГАУ, 2011. - №02(066). С. 535 - 545. - Шифр Информрегистра: 042110001210031, IDA [article ID]: 0661102045. - Режим доступа:http://ej.kubagro.ru/2011/02/pdf/45.pdf, 0,688 у.п.л.

14. Луценко Е.В. Исследование влияния подсистем различных уровней иерархии на эмерджентные свойства системы в целом с применением АСК-анализа и интеллектуальной системы "Эйдос" (микроструктура системы как фактор управления ее макросвойствами) / Е.В. Луценко // Политематический сетевой электронный научный журнал Кубанского государственного аграрного университета (Научный журнал КубГАУ) [Электронный ресурс]. - Краснодар: КубГАУ, 2012. - №01(075). С. 638 - 680. - Шифр Информрегистра: 042120001210025, IDA [article ID]: 0751201052. - Режим досту-

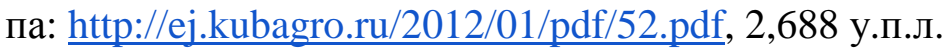

15. Луценко Е.В. Количественная оценка уровня системности на основе меры информации К. Шеннона (конструирование коэффициента эмерджентности Шеннона) / Е.В. Луценко // Политематический сетевой электронный научный журнал Кубанского государственного аграрного университета (Научный журнал КубГАУ) [Электронный peсурс]. - Краснодар: КубГАУ, 2012. - №05(079). С. 249 - 304. - IDA [article ID]: 0791205018. - Режим доступа: http://ej.kubagro.ru/2012/05/pdf/18.pdf, 3,5 у.п.л.

16. Луценко Е.В. Коэффициент эмерджентности классических и квантовых статистических систем / Е.В. Луценко, А.П. Трунев // Политематический сетевой электронный научный журнал Кубанского государственного аграрного университета (Научный журнал КубГАУ) [Электронный ресурс]. - Краснодар: КубГАУ, 2013. - №06(090). С. 214 - 235. - IDA [article ID]: 0901306014. - Режим доступа: http://ej.kubagro.ru/2013/06/pdf/14.pdf, 1,375 у.п.л.

17. Трунев А.П. Гравитационные волны и коэффициент эмерджентности классических и квантовых систем / А.П. Трунев, Е.В. Луценко // Политематический сетевой электронный научный журнал Кубанского государственного аграрного университета (Научный журнал КубГАУ) [Электронный ресурс]. - Краснодар: КубГАУ, 2014. №03(097). С. 1343 - 1366. - IDA [article ID]: 0971403092. - Режим доступа: http://ej.kubagro.ru/2014/03/pdf/92.pdf, 1,5 у.п.л.

18. Трунев А.П. Логарифмический закон и коэффициент эмерджентности классических и квантовых систем / А.П. Трунев, Е.В. Луценко // Политематический сетевой электронный научный журнал Кубанского государственного аграрного университета (Научный журнал КубГАУ) [Электронный ресурс]. - Краснодар: КубГАУ, 2016. №06(120). С. 1659 - 1685. - IDA [article ID]: 1201606110. - Режим доступа: http://ej.kubagro.ru/2016/06/pdf/110.pdf, 1,688 у.п.л.

\section{Literatura}

1. Sajt: evaluation.html

http://bazhenov.me/blog/2012/07/21/classification-performance-

2. Sajt: https://habrahabr.ru/post/228963/

3. Lucenko E.V. Universal'naja kognitivnaja analiticheskaja sistema «Jejdos". Monografija (nauchnoe izdanie). - Krasnodar, KubGAU. 2014. - 600 s. ISBN 978-5-94672-830-0. http://elibrary.ru/item.asp?id=22401787 
4. Orlov A.I., Lucenko E.V. Sistemnaja nechetkaja interval'naja matematika. Monografija (nauchnoe izdanie). - Krasnodar, KubGAU. 2014. - 600 s. ISBN 978-5-94672-757-0. http://elibrary.ru/item.asp?id=21358220

5. Lucenko E.V. Avtomatizirovannyj sistemno-kognitivnyj analiz v upravlenii aktivnymi ob\#ektami (sistemnaja teorija informacii i ee primenenie $\mathrm{v}$ issledovanii jekonomicheskih, social'no-psihologicheskih, tehnologicheskih i organizacionno-tehnicheskih sistem): Monografija (nauchnoe izdanie). - Krasnodar: KubGAU. 2002. - 605 s. http://elibrary.ru/item.asp?id=18632909

6. Amel'kin S.A. Ocenka jeffektivnosti rekomendatel'nyh sistem. http://rcdl.ru/doc/2012/paper44.pdf

7. Shevelev O.G. Metody avtomaticheskoj klassifikacii tekstov na estestvennom jazyke: Uchebnoe posobie. Tomsk: TML-Press, 2007. - 144c.

8. Lucenko E.V. Teoreticheskie osnovy i tehnologija adaptivnogo semanticheskogo analiza v podderzhke prinjatija reshenij (na primere universal'noj avtomatizirovannoj sistemy raspoznavanija obrazov "JeJDOS-5.1"). - Krasnodar: KJuI MVD RF, 1996. - 280s. http://elibrary.ru/item.asp?id=21745340

9. Lucenko E.V. Metrizacija izmeritel'nyh shkal razlichnyh tipov i sovmestnaja sopostavimaja kolichestvennaja obrabotka raznorodnyh faktorov v sistemno-kognitivnom analize i sisteme «Jejdos» / E.V. Lucenko // Politematicheskij setevoj jelektronnyj nauchnyj zhurnal Kubanskogo gosudarstvennogo agrarnogo universiteta (Nauchnyj zhurnal KubGAU) [Jelektronnyj resurs]. - Krasnodar: KubGAU, 2013 - №08(092). S. 859 - 883. - IDA [article ID]: 0921308058. - Rezhim dostupa: http://ej.kubagro.ru/2013/08/pdf/58.pdf, 1,562 u.p.1.

10. Lucenko E.V. Sintez adaptivnyh intellektual'nyh izmeritel'nyh sistem s primeneniem ASK-analiza i sistemy «Jejdos» i sistemnaja identifikacija v jekonometrike, biometrii, jekologii, pedagogike, psihologii i medicine / E.V. Lucenko // Politematicheskij setevoj jelektronnyj nauchnyj zhurnal Kubanskogo gosudarstvennogo agrarnogo universiteta (Nauchnyj zhurnal KubGAU) [Jelektronnyj resurs]. - Krasnodar: KubGAU, 2016. - №2(116). S. 1 60. - $\quad$ IDA [article ID]: 1161602001. - Rezhim dostupa: http://ej.kubagro.ru/2016/02/pdf/01.pdf, 3,75 u.p.1.

11.

https://yandex.ru/search/?msid=1478655999.15495.22884.13159\&text=kojefficienty \%20jemerdzhentnosti\%20Hartli\%20\%20Harkevicha\&lr=35

12. Lucenko E.V. Kolichestvennye mery vozrastanija jemerdzhentnosti v processe jevoljucii sistem (v ramkah sistemnoj teorii informacii) / E.V. Lucenko // Politematicheskij setevoj jelektronnyj nauchnyj zhurnal Kubanskogo gosudarstvennogo agrarnogo universiteta (Nauchnyj zhurnal KubGAU) [Jelektronnyj resurs]. - Krasnodar: KubGAU, 2006. №05(021). S. 355 - 374. - Shifr Informregistra: 042060001210089, IDA [article ID]: 0210605031. - Rezhim dostupa: http://ej.kubagro.ru/2006/05/pdf/31.pdf, 1,25 u.p.1.

13. Lucenko E.V. Obobshhennyj kojefficient jemerdzhentnosti Hartli kak kolichestvennaja mera sinergeticheskogo jeffekta ob\#edinenija buleanov $\mathrm{v}$ sistemnom obobshhenii teorii mnozhestv / E.V. Lucenko // Politematicheskij setevoj jelektronnyj nauchnyj zhurnal Kubanskogo gosudarstvennogo agrarnogo universiteta (Nauchnyj zhurnal KubGAU) [Jelektronnyj resurs]. - Krasnodar: KubGAU, 2011. - №02(066). S. 535 - 545. - Shifr Informregistra: 042110001210031, IDA [article ID]: 0661102045. - Rezhim dostupa:http://ej.kubagro.ru/2011/02/pdf/45.pdf, 0,688 u.p.l.

14. Lucenko E.V. Issledovanie vlijanija podsistem razlichnyh urovnej ierarhii na jemerdzhentnye svojstva sistemy v celom s primeneniem ASK-analiza i intellektual'noj sistemy "Jejdos" (mikrostruktura sistemy kak faktor upravlenija ee makrosvojstvami) / E.V. Lucenko // Politematicheskij setevoj jelektronnyj nauchnyj zhurnal Kubanskogo gosudarstvennogo agrarnogo universiteta (Nauchnyj zhurnal KubGAU) [Jelektronnyj resurs]. - Krasnodar: 
KubGAU, 2012. - №01(075). S. 638 - 680. - Shifr Informregistra: 0421200012 \0025, IDA [article ID]: 0751201052. - Rezhim dostupa: http://ej.kubagro.ru/2012/01/pdf/52.pdf, 2,688 u.p.l.

15. Lucenko E.V. Kolichestvennaja ocenka urovnja sistemnosti na osnove mery informacii K. Shennona (konstruirovanie kojefficienta jemerdzhentnosti Shennona) / E.V. Lucenko // Politematicheskij setevoj jelektronnyj nauchnyj zhurnal Kubanskogo gosudarstvennogo agrarnogo universiteta (Nauchnyj zhurnal KubGAU) [Jelektronnyj resurs]. - Krasnodar: KubGAU, 2012. - №05(079). S. 249 - 304. - IDA [article ID]: 0791205018. - Rezhim dostupa: http://ej.kubagro.ru/2012/05/pdf/18.pdf, 3,5 u.p.l.

16. Lucenko E.V. Kojefficient jemerdzhentnosti klassicheskih i kvantovyh statisticheskih sistem / E.V. Lucenko, A.P. Trunev // Politematicheskij setevoj jelektronnyj nauchnyj zhurnal Kubanskogo gosudarstvennogo agrarnogo universiteta (Nauchnyj zhurnal KubGAU) [Jelektronnyj resurs]. - Krasnodar: KubGAU, 2013. - №06(090). S. 214 - 235. - IDA [article ID]: 0901306014. - Rezhim dostupa: http://ej.kubagro.ru/2013/06/pdf/14.pdf, 1,375 u.p.1.

17. Trunev A.P. Gravitacionnye volny i kojefficient jemerdzhentnosti klassicheskih i kvantovyh sistem / A.P. Trunev, E.V. Lucenko // Politematicheskij setevoj jelektronnyj nauchnyj zhurnal Kubanskogo gosudarstvennogo agrarnogo universiteta (Nauchnyj zhurnal KubGAU) [Jelektronnyj resurs]. - Krasnodar: KubGAU, 2014. - №03(097). S. 1343 - 1366. - IDA [article ID]: 0971403092. - Rezhim dostupa: http://ej.kubagro.ru/2014/03/pdf/92.pdf, 1,5 u.p.l.

18. Trunev A.P. Logarifmicheskij zakon i kojefficient jemerdzhentnosti klassicheskih i kvantovyh sistem / A.P. Trunev, E.V. Lucenko // Politematicheskij setevoj jelektronnyj nauchnyj zhurnal Kubanskogo gosudarstvennogo agrarnogo universiteta (Nauchnyj zhurnal KubGAU) [Jelektronnyj resurs]. - Krasnodar: KubGAU, 2016. - №06(120). S. 1659 - 1685. - IDA [article ID]: 1201606110. - Rezhim dostupa: http://ej.kubagro.ru/2016/06/pdf/110.pdf, 1,688 u.p.l. 